\title{
The Effect of Atmospheric Transmissivity on Model and Observational Estimates of the Sea Ice Albedo Feedback
}

\author{
AARON DONOHOE \\ Applied Physics Laboratory, University of Washington, Seattle, Washington \\ ED BLANCHARD-WRIGGLESWORTH \\ Department of Atmospheric Sciences, University of Washington, Seattle, Washington \\ AXEL SCHWEIGER \\ Polar Science Center, Applied Physics Laboratory, University of Washington, Seattle, Washington \\ PHILIP J. RASCH \\ Pacific Northwest National Laboratory, Richland, Washington
}

(Manuscript received 9 September 2019, in final form 13 February 2020)

\begin{abstract}
The sea ice-albedo feedback (SIAF) is the product of the ice sensitivity (IS), that is, how much the surface albedo in sea ice regions changes as the planet warms, and the radiative sensitivity (RS), that is, how much the top-of-atmosphere radiation changes as the surface albedo changes. We demonstrate that the RS calculated from radiative kernels in climate models is reproduced from calculations using the "approximate partial radiative perturbation" method that uses the climatological radiative fluxes at the top of the atmosphere and the assumption that the atmosphere is isotropic to shortwave radiation. This method facilitates the comparison of RS from satellite-based estimates of climatological radiative fluxes with RS estimates across a full suite of coupled climate models and, thus, allows model evaluation of a quantity important in characterizing the climate impact of sea ice concentration changes. The satellite-based RS is within the model range of RS that differs by a factor of 2 across climate models in both the Arctic and Southern Ocean. Observed trends in Arctic sea ice are used to estimate IS, which, in conjunction with the satellite-based RS, yields an SIAF of $0.16 \pm 0.04 \mathrm{~W} \mathrm{~m}^{-2} \mathrm{~K}^{-1}$. This Arctic SIAF estimate suggests a modest amplification of future global surface temperature change by approximately $14 \%$ relative to a climate system with no SIAF. We calculate the global albedo feedback in climate models using model-specific RS and IS and find a model mean feedback parameter of $0.37 \mathrm{~W} \mathrm{~m}^{-2} \mathrm{~K}^{-1}$, which is $40 \%$ larger than the IPCC AR5 estimate based on using RS calculated from radiative kernel calculations in a single climate model.
\end{abstract}

\section{Introduction}

Sea ice area is expected to decrease as the climate system warms, and this in turn will lead to a darker surface, and an increase in solar radiation absorbed by the climate system. This additional radiative input reinforces the initial warming providing a positive climate feedback often termed the sea ice-albedo feedback (SIAF). Early literature on climate stability in simplified models suggested that SIAF could cause abrupt and

\footnotetext{
Corresponding author: Aaron Donohoe, adonohoe@u.washington. edu
}

dramatic climate state transitions under smoothly varying external forcing (North 1984; Budyko 1969) or produce multiple equilbria in more comprehensive coupled climate models (Ferreira et al. 2011). More modest estimates of the global albedo feedback (including changes associated in surface albedo over land) were found in coupled climate models (Stocker et al. 2013; Bony et al. 2006; Soden and Held 2006), producing an IPCC AR5 ensemble mean global albedo feedback of $0.26 \mathrm{~W} \mathrm{~m}^{-2} \mathrm{~K}^{-1}$ (Flato et al. 2013) leading to a $22 \%$ increase in the global climate response to external forcing (Roe 2009) relative to system with no surface albedo feedback. Pistone et al. $(2014,2019)$ used the covariance 
of year-to-year sea ice anomalies and satellite radiation to produce an observationally based estimate of SIAF with a similar magnitude for the Arctic sea ice $\left(0.31 \mathrm{~W} \mathrm{~m}^{-2} \mathrm{~K}^{-1}\right)$ and pointed out this additional radiative input to the climate system due to Arctic ice melt to date $25 \%$ the anthropogenic forcing. There is still a substantial $\left( \pm 0.1 \mathrm{~W} \mathrm{~m}^{-2} \mathrm{~K}^{-1}\right)$ intermodel spread in strength of the SIAF (Winton 2006; Hall and Qu 2006) that is understood to be the leading cause of intermodel differences (Hall 2004; Kay et al. 2012) in the highlatitude climate response (polar amplification; Holland and Bitz 2003).

SIAF measures how much additional radiative energy the Earth system gains due to sea ice loss as the planet warms, which amplifies the warming relative to a system with no SIAF. SIAF is quantified as the global (area weighted) average of $\mathrm{RI}_{\mathrm{TOA}, \alpha}$, the radiative impact of sea ice change [the local top-of-atmosphere (TOA) radiative flux change due to surface albedo changes $(\alpha)$ from sea ice loss per degree of global averaged surface temperature change]:

$$
\mathrm{SIAF}=\left[\mathrm{RI}_{\mathrm{TOA}, \alpha}(x, y)\right],
$$

where square brackets indicate a global average. Following Winton (2006) [Eq. (1)], the spatial map of $\mathrm{RI}_{\mathrm{TOA}, \alpha}(x, y)$ is the product of two quantities (Soden and Held 2006; Shell et al. 2008): 1) the surface albedo change due to sea ice loss per unit of global mean surface temperature change, $\left[d T_{S}\right],\left(d \alpha_{\mathrm{SI}} /\left[d T_{S}\right]\right)$, and 2) the sensitivity of TOA radiation to surface albedo $\left(\partial \mathrm{RAD}_{\mathrm{TOA}} / \partial \alpha\right)$ that we hereafter refer to as radiative sensitivity (RS):

$$
\mathrm{RI}_{\mathrm{TOA}, \alpha}(x, y)=\underbrace{\frac{d \alpha_{\mathrm{SI}}}{\left[d T_{S}\right]}}_{\mathrm{IS}(x, y)} \underbrace{\frac{\partial \mathrm{RAD}_{\mathrm{TOA}}(x, y)}{\partial \alpha(x, y)}}_{\mathrm{RS}(x, y)} .
$$

The normalization of $\mathrm{RI}_{\mathrm{TOA}, \alpha}(x, y)$ by global mean temperature $\left(T_{S}\right)$ change is integrated into the IS term and RS is defined as the local radiative change at the TOA per unit of surface albedo change. This study considers only the radiative impact of $\alpha$ changes in high latitudes [poleward of $60^{\circ} \mathrm{N}$ and $55^{\circ} \mathrm{S}$, in the Northern and Southern Hemispheres ( $\mathrm{NH}$ and $\mathrm{SH}$ ), respectively] over oceans, and calculations of SIAF exclude the impact of changes in terrestrial snow cover. RS and $\alpha$ changes are calculated for each month and then their product is time averaged. Changes in $\alpha_{\mathrm{SI}}$ are calculated over the ocean and capture both the impact of sea ice loss and changes in surface albedo over sea ice (i.e., snow and melt ponds). Hall and Qu (2006) claim that RS varies very little between climate models. As a result, much of the literature on SIAF uncertainty has focused on processes controlling sea ice albedo changes and the sensitivity of sea ice concentration (SIC) to warming (Winton 2006; Qu and Hall 2005; Curry et al. 1995), which both vary substantially between models. The IPCC estimate of the global albedo feedback (Flato et al. 2013; Soden and Held 2006) used a RS calculated from a single model, neglecting intermodel differences and biases (relative to observations) and assuming RS does not contribute to albedo feedback uncertainty. We assess the validity of this assumption in this work.

RS depends primarily on cloud reflectivity; clouds impede the amount of downwelling solar radiation reaching the surface and also reduce the amount of solar radiation reflected by the surface from reaching the TOA (Taylor et al. 2007; Donohoe and Battisti 2011), leading to a quadratic dependence of RS on cloud reflectivity. High-latitude cloud properties vary substantially between models and exhibit many biases relative to observations (Gorodetskaya et al. 2008; Vavrus et al. 2009; Trenberth and Fasullo 2010). Cloud differences can contribute to model differences in RS that in turn influence 1) the sensitivity of sea ice loss to future warming (Hwang et al. 2011) via local positive radiative feedbacks and 2) the impact of sea ice loss on the global energy budget and, thus, the global climate sensitivity to external forcing.

This study assesses intermodel differences in RS and consistency compared to estimates from satellite observations. We also identify relative contributions of IS and RS to model spread and biases (relative to observations) in the amplification of global warming by SIAF, and evaluate the impact of using RS from a single climate model to calculate the global surface albedo feedback across models as was done in Soden and Held (2006) and the IPCC AR5 estimate of surface albedo feedback.

The manuscript is organized as follows: section 2 outlines how a simplified isotropic model often discussed in textbooks on radiative transfer, and further developed by Taylor et al. (2007), can be used to calculate RS from standard climate model output and demonstrates that the method reproduces results from more computationally demanding radiative kernel techniques. This facilitates further evaluation of intermodel spread in RS in the coupled models participating in the Coupled Model Intercomparison Project (CMIP3 and CMIP5; Meehl et al. 2007; Taylor et al. 2012). Most importantly, this method also provides an observational estimate of RS from satellite data (section 3). These estimates of RS along with the sea ice response over the historical period are used to calculate an observational SIAF (section 4). The observational SIAF is compared 

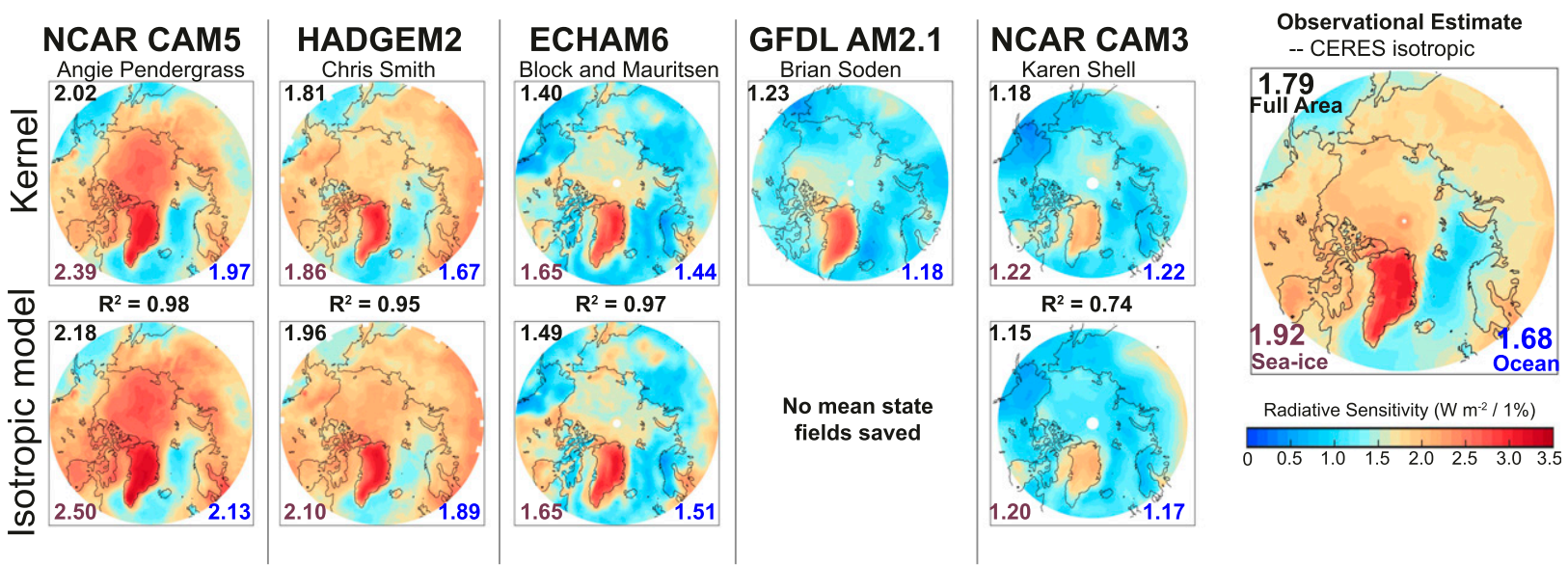

FIG. 1. Arctic summertime (MJJA) surface albedo radiative sensitivity (RS) (top) calculated from radiative kernels and (bottom) estimated from the climatological radiative fields using the idealized isotropic radiation model in the same models. The squared spatial correlation coefficient between the kernel isotropic methods in the same model are provided in the middle and the Arctic domainaveraged values are shown in the top right of each panel. Note that there is no RS calculation from the GFDL model because mean state fields from this simulation were not saved. Observational estimates from CERES EBAF satellite data and the isotropic model are shown to the right.

to that in model simulations under historical forcing and $4 \times \mathrm{CO}_{2}$ and the model spread and biases are decomposed into contributions from RS and IS (section 5). In section 6 , we evaluate the impact of the intermodel spread in RS on the global surface albedo feedback calculated in the IPCC report. A summary and discussion follow.

\section{The impact of surface albedo changes on TOA radiation in radiative kernels and a simplified model}

\section{a. Radiative kernels}

The impact of surface albedo changes on TOA radiation (RS) has been rigorously calculated using radiative kernel techniques in a small number of climate models (Smith et al. 2018; Pendergrass et al. 2018; Shell et al. 2008; Block and Mauritsen 2013; Soden and Held 2006; Previdi 2010). RS can be calculated directly from offline radiative model calculations by prescribing changes to the surface albedo $(\alpha)$ at each grid point and then running the radiative code with all other fields unchanged-a technique referred to as a radiative kernel calculation (Soden and Held 2006; Shell et al. 2008). Radiative kernels are generally calculated at each grid point over a global domain by perturbing the surface albedo at each grid point by a specified amount (independent of whether that surface albedo change is feasible) using atmospheric models with prescribed historical climatological (seasonally varying) sea surface temperatures. We use kernel calculations (for specific models) provided by 1) Karen Shell, NCAR CAM3 (Shell et al. 2008); 2) Karoline Block, MPI ECHAM6 (Block and Mauritsen 2013); 3) Angie Pendergrass, NCAR CAM5 (Pendergrass et al. 2018); 4) Chris Smith, UKMO HadGEM2 (Smith et al. 2018); and 5) Brian Soden, GFDL AM2p12b (Soden and Held 2006).

RS is reported in $\mathrm{W} \mathrm{m}^{-2} \%^{-1}$ where the \% refers to a 0.01 unit change in surface albedo (independent of the climatological surface albedo). Summertime [MayAugust (MJJA)] daily-averaged TOA insolation in the Arctic (defined as the region poleward of $60^{\circ} \mathrm{N}$ ) is on the order of $420 \mathrm{~W} \mathrm{~m}^{-2}$, and a $4.2 \mathrm{~W} \mathrm{~m}^{-2} \%^{-1} \mathrm{RS}$ would be expected in a completely transparent atmosphere. Radiative kernel calculations produce an RS Arctic average of $1.63 \mathrm{~W} \mathrm{~m}^{-2} \%^{-1}$ across the four different models (numbers in the upper right of each panel in Fig. 1), indicating that the atmosphere attenuates the surface contribution to reflected radiation at the TOA by a factor of $\sim 2.6(4.2 / 1.63)$. Kernel estimates of RS in Arctic summer (May-August) are largest over Greenland $\left(2-3.5 \mathrm{~W} \mathrm{~m}^{-2} \%^{-1}\right)$ and smallest in the GreenlandIceland-Norwegian (GIN) Seas $\left(0.5-1 \mathrm{~W} \mathrm{~m}^{-2} \%^{-1}\right)$, with intermediate values in the central Arctic (1-2.5 $\mathrm{W} \mathrm{m}^{-2} \%^{-1}$; upper panels of Fig. 1). This spatial structure primarily reflects the climatological pattern of solar radiation reaching the surface in the Arctic (Lindsay et al. 2014). The highest RS values are found where cloud cover and water vapor are low over the high topography of Greenland. Moderate RS values are seen in the central Arctic due to the thin but persistent cloud 

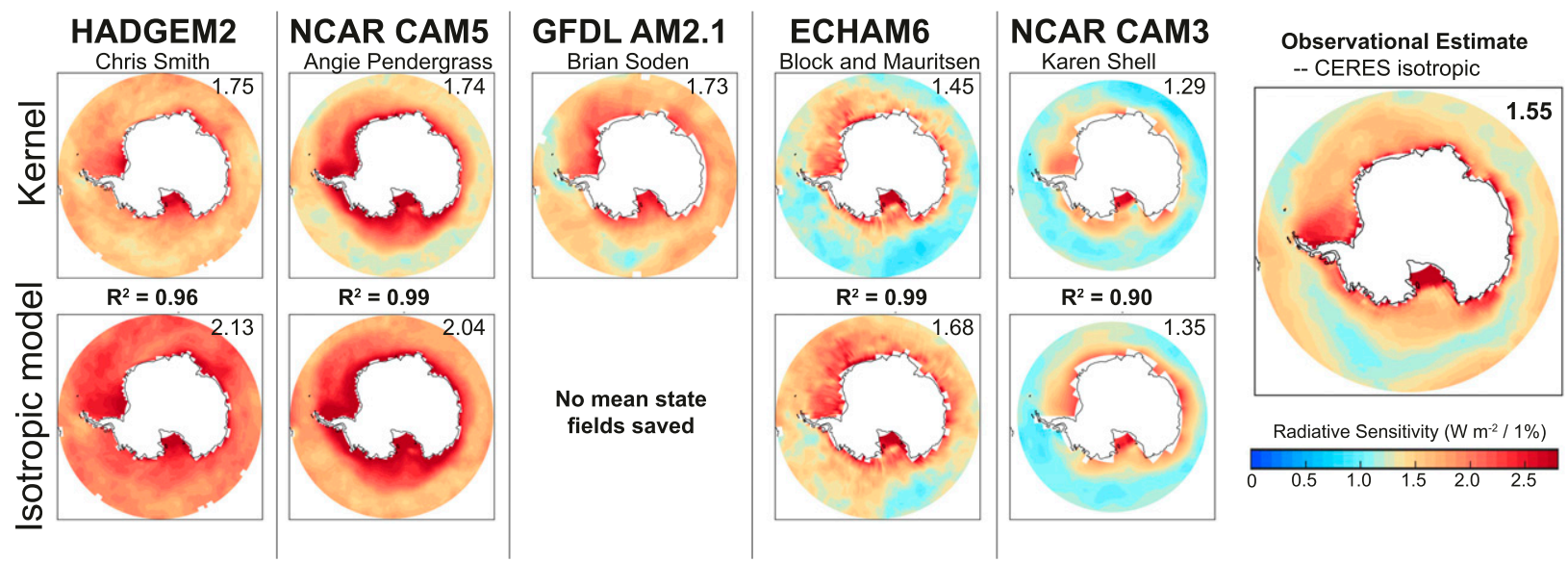

FIG. 2. As in Fig. 1, but for the NDJF RS in the Southern Ocean. Domain-averaged surface albedo feedbacks exclude the Antarctic continent. Note that the figures are ordered by domain average RS over the Southern Ocean and this order differs from Fig. 1.

cover over the perennial sea ice. RS is smallest in the GIN Seas due to abundant thick clouds.

There is remarkable intermodel spread in Arctic RS across the different radiative kernel calculations, especially over the central Arctic where the models differ by a factor of 2 . As shown below, the diversity of RS across the different kernel calculations is a consequence of intermodel differences in the mean state cloudiness and not due to differences in radiative transfer code or the methodology used to calculate the kernels between the different groups.

In the SO, RS during the austral summer [NovemberFebruary (NDJF)] calculated from radiative kernels shows a zonally annular structure in all models with smaller values over the cloudy storm track region equatorward of the ice edge and larger values over the sea ice (upper panels of Fig. 2). However, the models differ to first order on the magnitude of RS over the open ocean and on the location and aerial extent of the region of larger RS adjacent to the Antarctic continent. In HadGEM2, the value of RS over the open ocean is $2 \mathrm{~W} \mathrm{~m}^{-2} \%^{-1}$ whereas in NCAR CAM3 RS is $1 \mathrm{~W} \mathrm{~m}^{-2} \%^{-1}$ over the same region. In NCAR CAM5, the region of high RS adjacent to the Antarctic coast extends substantially into the SO whereas in NCAR CAM3 and ECHAM6 the high RS region is confined to the coast itself with the exception of the Weddell and Ross Seas. The intermodel differences in the aerial extent of the high RS region roughly correspond to intermodel biases in summertime ice extent; the gradient in atmospheric tranmissivity is linked to the sea ice edge via cloud coverage and atmospheric water content although in some models the gradient in cloudiness is significantly poleward of the ice edge (i.e., NCAR CAM3) while in other models the cloud gradient is collocated with the ice edge (i.e., NCAR CAM5). Overall, the Southern Ocean domain average RS (excluding the Antarctic continent to focus on the sea ice) ranges from 1.29 to $1.75 \mathrm{~W} \mathrm{~m}^{-2} \%^{-1}$ (as shown by the values in the upperright corner of Fig. 2).

\section{b. Isotropic single-layer model}

Taylor et al. (2007, hereafter T07) developed a model (hereafter the isotropic model) that can be used for approximating RS from the climatological radiative fluxes at the TOA and surface and some basic assumptions about shortwave radiative transfer in the atmosphere. Part of the T07 derivation is repeated here for clarity with a few modifications to variable names. Of the incident shortwave radiation at the TOA $(S)$, assume a fraction $(A)$ is absorbed in the atmosphere above cloud top and a fraction $R$ of the radiation incident on cloud top is reflected back to space (Fig. 3). This resultant downwelling radiation at the surface is $S(1-A)(1-R)$. A fraction ( $\alpha$, equal to the surface albedo) of this downwelling radiation is reflected upward. Of this surface upwelling radiation, $R$ is reflected back (downward) to surface with the remainder $[S(1-$ $\left.A)(1-R)^{2}\right]$ transmitted to space. Reflections and transmissions are continued indefinitely subject to the three primary assumptions: 1) cloud optical properties can be represented by a single layer, 2) cloud reflection is isotropic-the same fraction $(R)$ of broadband shortwave radiation incident on the cloud layer is reflected independent of the direction (upwelling/downwelling) and how many previous interactions with the surface and cloud occur, and 3) all of the atmospheric absorption occurs above cloud top on the first downward pass which is apt for describing SW absorption by ozone in the stratosphere (Chou and Lee 1996). We 


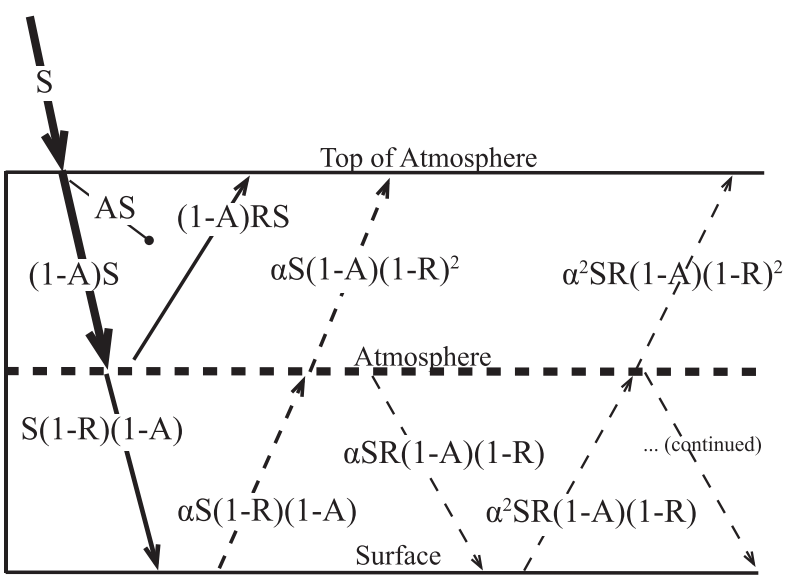

FIG. 3. Schematic of the single layer isotropic model modified from $\mathrm{T} 07$.

further analyze the limitations of these assumptions at the end of this subsection.

In the isotropic model, loss of shortwave radiative energy from the climate system due to surface albedo is a three-step process: 1) insolation must be transmitted to the surface, then 2) reflected by the surface, and finally 3) transmitted from the surface to the TOA. Mathematically, upwelling SW radiation at the TOA that results from reflection off the surface is equal to the insolation $(S)$ times the downwelling transmissivity $[(1-A)(1-R)]$ times the upwelling transmissivity $(1-R)$. The isotropic model also includes higher-order reflections where the SW radiation reflected at the surface is reflected back to the surface off clouds and thereafter will contribute additional upwelling SW fluxes at the TOA with each subsequent reflection equal to the value of the previous order contribution times $\alpha R$. These terms form an infinite geometric series that converges to the expression

$$
\mathrm{SW} \uparrow_{\mathrm{TOA}}=\underbrace{\mathrm{SR}(1-A)}_{\mathrm{SW}_{\mathrm{TOA}, \text { atmos }}}+\underbrace{S \alpha \frac{(1-A)(1-R)^{2}}{1-\alpha R}}_{\mathrm{SW} \uparrow_{\mathrm{TOA}, \text { surf }}},
$$

where $\mathrm{SW} \uparrow_{\text {тоA,atmos }}$ and $\mathrm{SW} \uparrow_{\text {тоA,surf }}$ indicate the upwelling radiation at the TOA that was derived from atmospheric and surface reflection respectively. Thus, if the values of $R$ and $A$ along with $\alpha$ and $S$ are known, the contribution of the surface to the SW flux at the TOA can be calculated. In our case, the isotropic model provides equations relating three satellite-derived quantities ( $\mathrm{SW} \uparrow_{\text {TOA }}, \mathrm{SW} \uparrow_{\mathrm{SURF}}$, and $\left.\mathrm{SW} \downarrow_{\mathrm{SURF}}\right)$ in terms of three unknown variables $(A, R, \alpha)$ and the satellite measured $S$. The result is a determined set of three equations in terms of three variables. Thus, the climatological radiative fluxes allow the calculation of the single-pass $A$ and $R$ for each climate model. We can then calculate the expected change of SW $\uparrow$ TOA as $\alpha$ changes with all else being equal by taking the partial derivative of Eq. (3) with respect to $\alpha$ :

$$
\mathrm{RS}=\frac{\partial \mathrm{SW} \uparrow_{\mathrm{TOA}}}{\partial \alpha}=S \frac{(1-A)(1-R)^{2}}{1-\alpha R}\left(1+\frac{R \alpha}{1-R \alpha}\right) .
$$

This provides an alternate method for calculating RS that relies only on readily available model output at monthly resolution that can also be compared with the RS calculated from radiative kernel techniques.

The lower panels of Fig. 1 show the RS in the Arctic summer calculated from Eq. (4) applied to the monthly climatological output from the same control simulations that were used to calculate the radiative kernels. The RS calculated from the isotropic model is in good agreement with that calculated from radiative kernels in terms of the spatial pattern of RS and intermodel differences. Spatial correlation between RS in the isotropic model and radiative kernel calculation for each model is high with an $R^{2}$ that exceeds $95 \%$ in all but NCAR CAM3. The intermodel differences in domain average of RS is within $10 \%$ in the absolute sense and captures the rank of RS in models (cf. the adjacent upper and lower panels of Fig. 1 with $R^{2}$ listed in the middle). The isotropic model explains $94 \%$ of the variance in MJJA RS calculated from radiative kernels considered across models and over all Arctic grid points collectively with a root-mean-square (RMS) error of $0.15 \mathrm{~W} \mathrm{~m}^{-2} \%^{-1}$ (see the top panel of Fig. A2 in the appendix). As a basis for comparison, if one used the spatial pattern of MJJA RS calculated using radiative kernels from one model to predict the kernel based RS in a different model—as was done in the IPCC estimate of SIAF- the RS variance explained is $21 \%$ with a RMS error of $0.67 \mathrm{~W} \mathrm{~m}^{-2} \%^{-1}$ (bottom panel of Fig. A2). Thus, the isotropic model offers a factor of 4 improvement on the practice of applying RS calculations from a single climate model.

The isotropic model also captures the spatial pattern and intermodel spread of the kernel calculated RS in the SO (Fig. 2) although the absolute values of RS differs by as much as $20 \%$ (in the HadGEM 2 model). The isotropic model explains $96 \%$ of the variance in NDJF kernel RS across models over the SO (top panel of Fig. A3) with an RMS error of $0.23 \mathrm{~W} \mathrm{~m}^{-2} \%^{-1}$. When radiative kernels from one model are used to predict the kernel-based NDJF RS in a different model the variance explained is $71 \%$ with a RMS error of $0.47 \mathrm{~W} \mathrm{~m}^{-2} \%^{-1}$ (bottom panel of Fig. A3). Thus, the isotropic model offers a factor of 2 improvement on the practice of applying RS calculations from a single climate model in the 


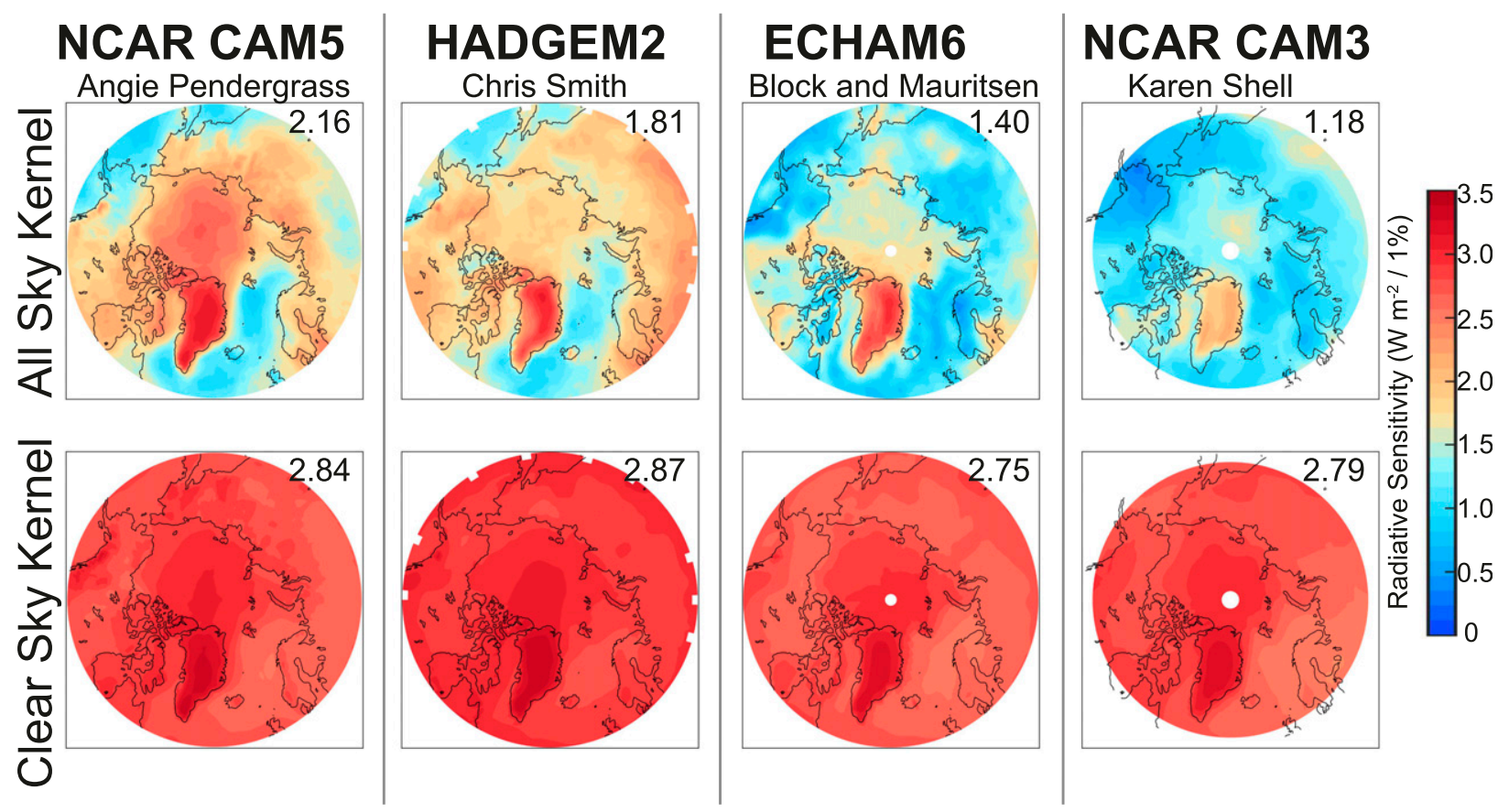

FIG. 4. Comparison of Arctic summertime (MJJA) full-sky and clear-sky surface albedo kernels.

SO. These results indicate that the isotropic model captures the essential SW radiative processes that determine the RS of surface albedo changes, and that the intermodel spread in RS is determined by the climatological cloud reflectivity which is adequately calculated from the modeled TOA and surface fluxes according to Eq. (3).

The isotropic model tends to bias the RS high relative to the radiative kernel (cf. the domain average values listed in the upper right of the map in the upper and lower panels of Figs. 1 and 2) and we speculate that this results from the simplifying assumption that atmospheric absorption only occurs during the first pass as this allows more of the radiation reflected off the surface to be transmitted to space than would occur if the atmosphere absorbed upwelling solar radiation. Alternative formulations of similar isotropic models (Donohoe and Battisti 2011) assume the atmospheric absorption occurs in the same layer as the cloud reflection and occurs on all passes through the atmosphere to account for shortwave absorption by water vapor that occurs throughout the troposphere (Donohoe and Battisti 2013). This model better matches the RS calculated by radiative kernels in the tropics and midlatitudes but substantially underestimates RS relative to the radiative kernel derived value at high latitudes (Fig. A1). We speculate that in the dry Arctic the atmospheric absorption is primarily by stratospheric ozone whereas in the lower latitudes water vapor also contributes. For this reason, we choose to assume that absorption occurs only on the downward pass and return to possible impacts and improvements of this method in the discussion section.

\section{c. Causes of intermodel spread in RS}

What processes are responsible for the factor of 2 spread in modeled RS in Figs. 1 and 2? The ability of the isotropic model to reproduce the kernel-based RS calculated for each model demonstrates that the mean state atmospheric opacity is the primary determinant. Generally speaking, RS is determined by how much insolation is transmitted to the surface and thus how much impact surface albedo changes have on reflected solar radiation. More specifically, RS is proportional to the atmospheric transmissivity squared with higherorder modifications due to the impact of multiple reflections [Eq. (4)]. What then causes the intermodel spread in atmospheric opacity?

Clear-sky surface albedo kernels (Fig. 4) have much larger magnitudes than their all-sky counterparts. The very similar spatial structures and absolute values in the four models with available kernel calculations have domain averages that differ by $2 \%$ from the multimodel mean, indicating that 1) clear-sky processes are not responsible for the intermodel spread in all-sky RS and 2) the different radiative transfer codes used in the climate models find a similar RS for a similar (clear sky) mean state. 


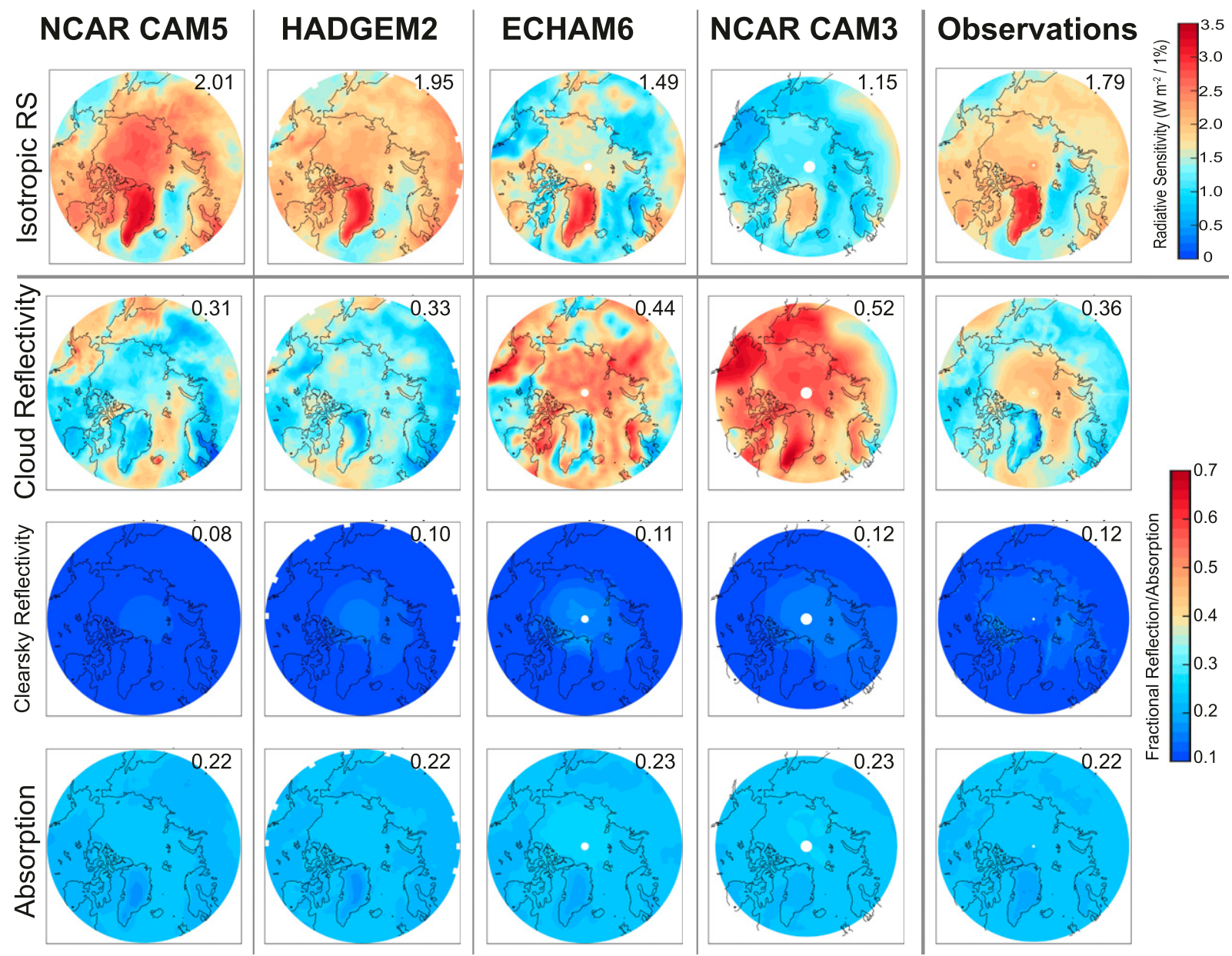

FIG. 5. Comparison of the atmospheric opacity parameters that result from the application of the isotropic model to the Arctic summertime (MJJA) mean state radiative fields in the different climate models and observations. (top) All-sky RS repeated from Fig. 1. (middle) Cloud reflectivity defined as the isotropic reflectivity applied to the all-sky radiative fields minus that defined from the clear-sky fields with the latter shown in the third row. (bottom) All-sky absorptivity. The (full Arctic) domain average is shown in the top right of each panel. The four models for which kernels are available are shown in the left columns and the observational calculation from CERES data is shown to the right.

The atmospheric opacity parameters-reflectivity and absorptivity - calculated by the isotropic model applied to the mean states of the different climate models are shown in Fig. 5. The all-sky reflectivity is subdivided into a clear-sky and cloud component by applying the isotropic model to the clear-sky mean state radiative fields (as in T07) to define a clear-sky reflectivity, and the cloud reflectivity is then defined as the all-sky minus clear-sky reflectivity. All climate models have very similar and nearly spatially uniform clear-sky reflectivity and all-sky absorptivity with Arctic domain average absolute differences from the model mean of order 0.02 fractional units. The slight spatial structure in clear-sky reflectivity and absorptivity is consistent between climate models. Clear-sky reflectivity is larger near the North Pole consistent with enhanced Rayleigh scattering due to the shallower angle of incidence with latitude. Absorptivity is smaller over the thinner atmosphere above topography and drier continents consistent with reduced absorption by water vapor. In contrast to the consistency of absorption and clear-sky reflection between models, the cloud reflectivity differs substantially between models in both spatial structure and domain average values (which differ between models by over 0.20 fractional units). In general, regions of stronger cloud reflectivity have smaller RS values consistent with less downwelling solar radiation at the surface in cloudy regions. However, the anticorrelation between the spatial variability in RS and cloud reflectivity is significant but far from perfect $(R \approx-0.60)$ within a given climate model due to the (comparable in magnitude) impact of the spatial structure of mean state 

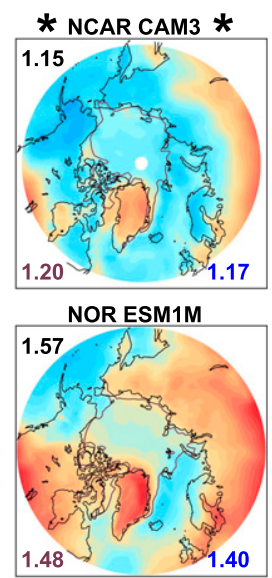

IPSL CM5 RUN B
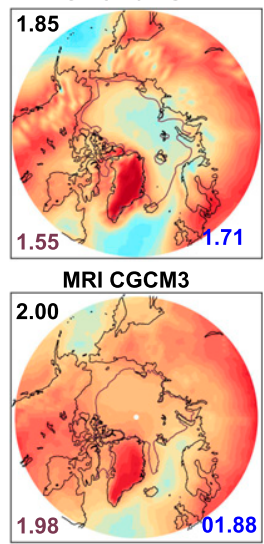
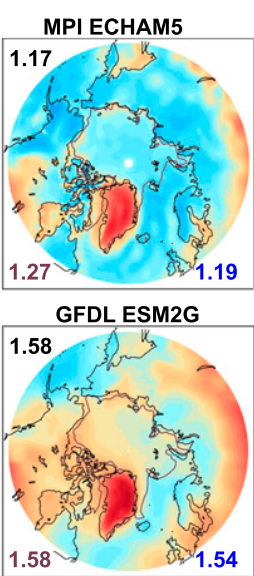

IPSL CM5 RUN A

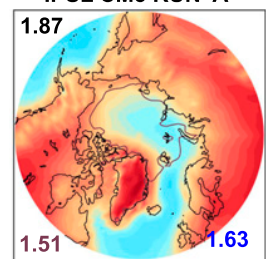

MIROC 5

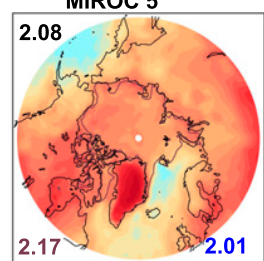

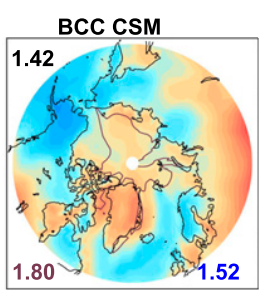

CSIRO MK5

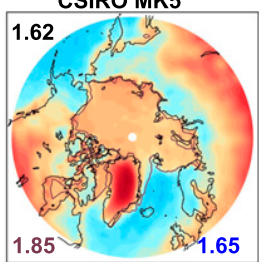

ACCESS 1.0

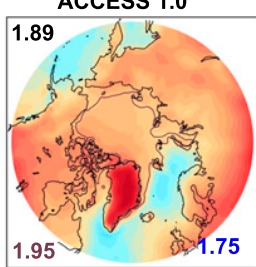

CNRM CM5

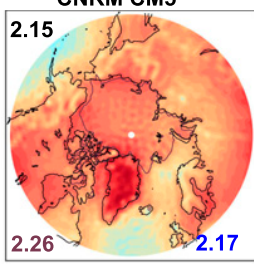

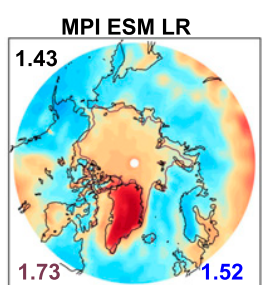
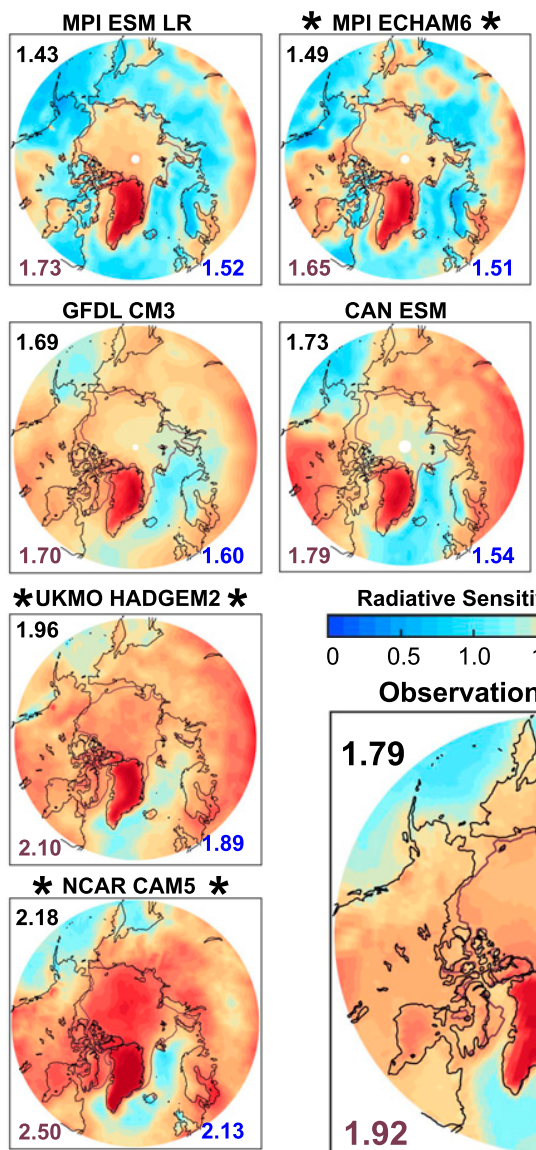
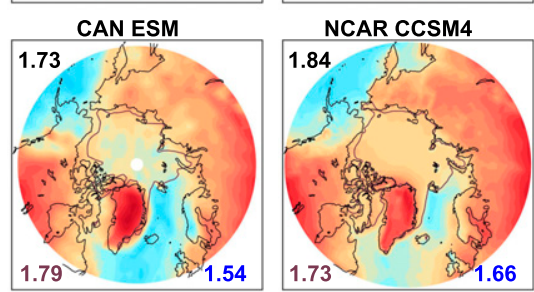

Radiative Sensitivity (W m $\mathrm{m}^{-2}$ per 0.01)

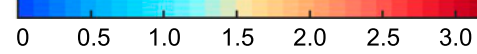

Observations -- CERES

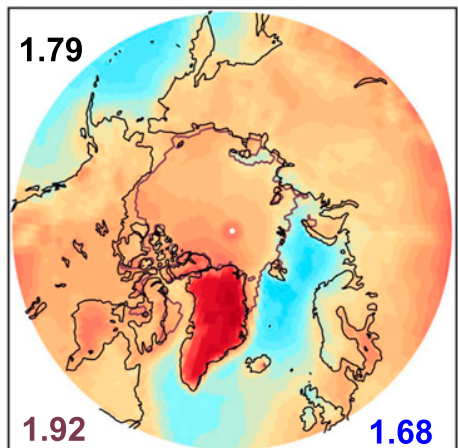

FIG. 6. Arctic summertime (MJJA) radiative sensitivity estimated using the isotropic model and the climatological radiation fields for CMIP5 historical simulations. Models are ordered as in reading a book (left to right then down) according to the domain average albedo feedback. Asterisks denote the models for which radiative kernel calculations are available that have been repeated from Fig. 1. The dark purple line shows the sea ice edge designated by the MJJA 50\% sea ice concentration contour. The full domain spatial average is shown in the top left corner of each panel in black, the Arctic Ocean average is shown in the lower right corner in blue, and the spatial average over the sea ice is shown in the lower left corner in purple. Observational estimates from CERES satellite data are shown in the bottom right panel.

albedo [Eq. (4)] on the multiple reflection contribution to RS. On a broader scale, the Arctic domain average cloud reflectivity is very strongly anticorrelated $(R=-0.99)$ with the domain average RS. indicating that Arctic averaged RS is primarily determined by the mean state cloud reflectivity.

\section{Observational estimate of radiative sensitivity to surface albedo changes and comparison to coupled models}

Given the strong correspondence between RS calculated from radiative kernels and the isotropic model (Figs. 1 and 2), we can use the isotropic model to calculate RS from observational estimates of radiative fluxes at the TOA and surface and use these same fields (routinely available from model simulations) to assess model biases in RS and diagnose their role in the SIAF.

Observational estimates of climatological radiative fluxes are taken from the CERES EBAF surface product version 4.0 (Loeb et al. 2018; Kato et al. 2018) between 2000 and 2018. Climate model RS is estimated using the isotropic model for the last decade (19952005) of historical CMIP5 (Taylor et al. 2012) climate simulations forced. ${ }^{1}$

Maps of summer (MJJA) RS estimated from satellite products and models are shown in Fig. 6. Three spatial averages of RS are also provided: 1 ) the whole domain poleward of $60^{\circ} \mathrm{N}$ (upper left corner in black), with an

\footnotetext{
${ }^{1}$ Most of the radiative kernel calculations discussed in section 2 used "modern," slightly differing time periods.
} 

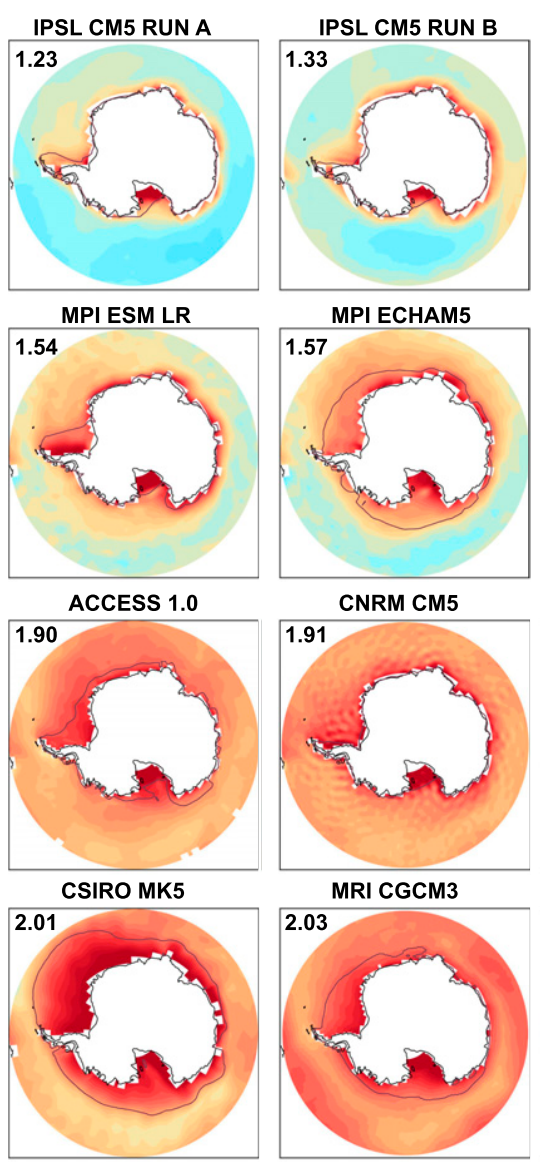
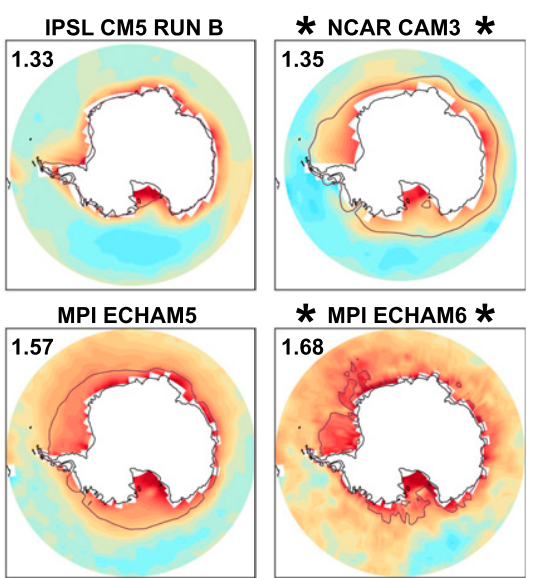

CNRM CM5
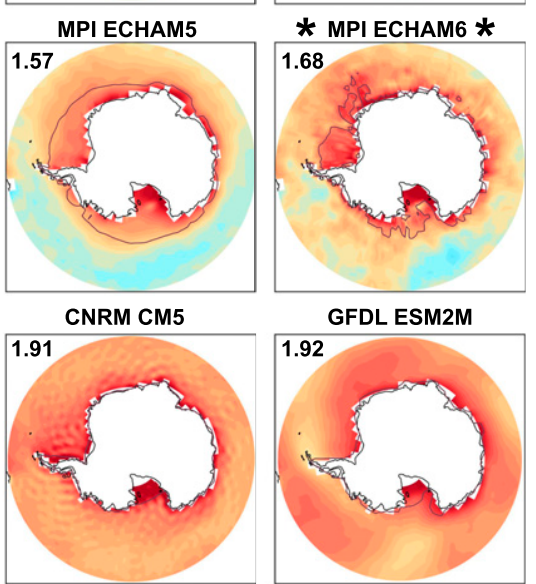

GFDL ESM2M
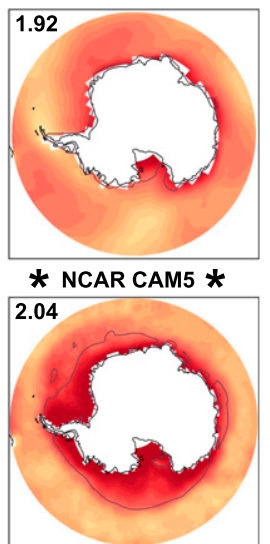
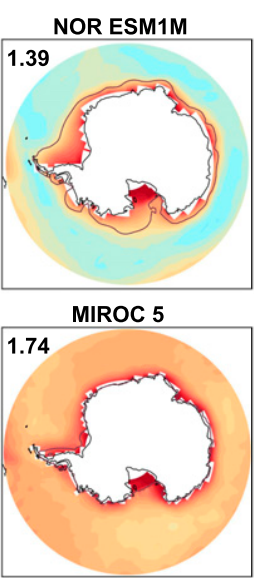

GFDL ESM2G
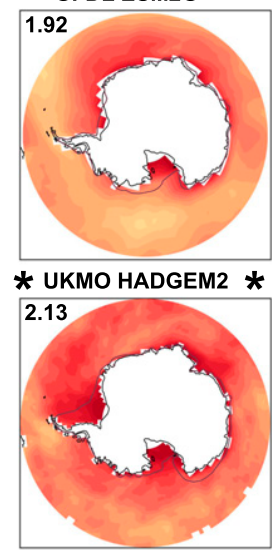
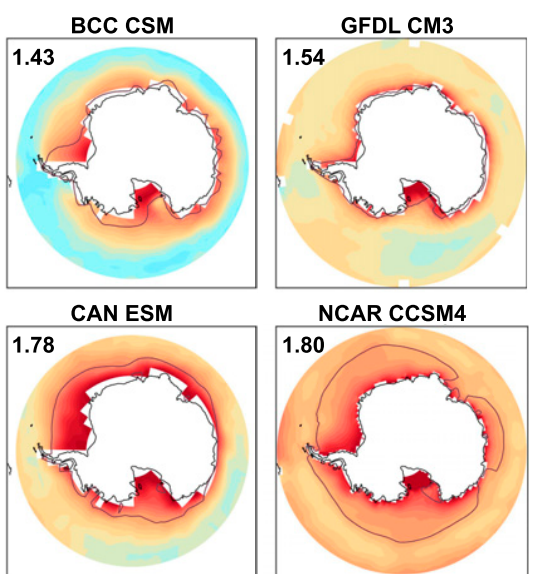

NCAR CCSM4

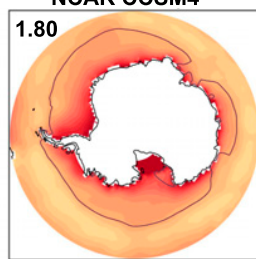

Radiative Sensitivity $\left(\mathrm{W} \mathrm{m}^{-2}\right.$ per 0.01$)$

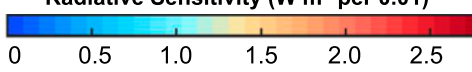

Observations -- CERES

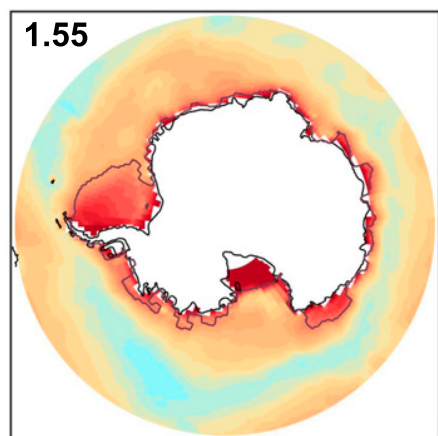

FIG. 7. As in Fig. 6, but for the NDJF Southern Ocean RS. Domain-averaged surface albedo feedbacks exclude the Antarctic continent. The dark purple line shows the sea ice edge designated by the NDJF $50 \%$ sea ice concentration contour. Note that models are ordered by Southern Ocean domain averaged RS and this order differs from that in Fig. 6. Asterisks denote the models for which radiative kernel calculations are available that have been repeated from Fig. 2.

observational value of $1.79 \mathrm{~W} \mathrm{~m}^{-2} \%^{-1}$; 2) the Arctic Ocean excluding landmasses (lower right in blue), with an observational value of $1.68 \mathrm{~W} \mathrm{~m}^{-2} \%^{-1}$; and 3 ) the spatial average over the sea ice (the spatial footprint and region varies between models, lower left in purple), with an observational value of $1.92 \mathrm{~W} \mathrm{~m}^{-2} \%^{-1}$. The observational RS is very similar to multimodel mean values $\left(1.72,1.65\right.$, and, $1.79 \mathrm{~W} \mathrm{~m}^{-2} \%^{-1}$ over the entire Arctic domain, Arctic Ocean, and sea ice regions respectively). The models and observations generally agree on the spatial pattern of RS over the Arctic with high values over the Greenland Ice Sheet where the reduced mass of the atmosphere above the high topography is associated with enhanced atmospheric SW tranmissivity, lower RS values over the GIN Seas, and more spatially uniform RS values over the central Arctic. The magnitude of RS differs substantially across models with domain average RS varying by almost a factor of 2 between the models, consistent with results from the radiative kernel-based
RS calculation (Fig. 1). The intermodel $(2 \sigma)$ spread in Arctic average RS is $0.57,0.53$, and, $0.64 \mathrm{~W} \mathrm{~m}^{-2} \%^{-1}$ over the full Arctic domain, Arctic Ocean, and climatological sea ice respectively.

The SO observational estimate of summertime (NDJF) RS is similar but slightly lower (domain average excluding the Antarctic continent of $1.56 \mathrm{~W} \mathrm{~m}^{-2} \%^{-1}$ ) than the multimodel mean $\left(1.71 \mathrm{~W} \mathrm{~m}^{-2} \%^{-1}\right)$. All models and observations show an annular structure in RS with smaller values in the storm track region and larger values adjacent to the Antarctic continent over the sea ice (Fig. 7). RS differs substantially between models (on the order of a factor of 2) in the storm track region and on the location and lateral extent of the high RS region adjacent to the continent. Some models (i.e., CSIRO Mk5) also have zonal asymmetries in RS that are best characterized as a zonal wavenumber-1 pattern. The domain average RS values differ by less than the factor of 2 differences seen in the Arctic, but the 
local RS difference between models-especially in the storm track region-are on the order of a factor of 2 . The intermodel $(2 \sigma)$ spread in SO average $\mathrm{RS}$ is $0.54 \mathrm{~W} \mathrm{~m}^{-2} \%^{-1}$, comparable in magnitude to that over the Arctic domain and Arctic Ocean.

These results collectively suggest that while CMIP5 ensemble average RS of high-latitude ice loss is quite similar to that implied from observational constraints, models diverge substantially on the radiative impact of ice loss because of differences in atmospheric optical properties (i.e., clouds).

\section{Observational estimate of ice albedo feedback}

The Arctic sea ice-albedo feedback (SIAF) is (the spatial average of) the product of the RS-the TOA radiative impact of surface albedo changes-and the ice sensitivity (IS), namely the surface albedo change due to Arctic sea ice loss per unit of global warming [Eqs. (1) and (2)]. Thus, the RS calculated from the climatological radiative fluxes and the isotropic model in the previous sections along with estimates of IS from the observational record provide an observational estimate of the SIAF that can be compared to the SIAF calculated using the same methodology applied to CMIP5 simulations with historical and long-term forcing. Furthermore, we can explicitly ask if the model spread (and potential bias relative to observations) in SIAF is explained by RS or IS spread.

The observational estimate of IS is calculated from the changes in decadal surface albedo of the Arctic ocean from 1982 to 2016 (2007-16 average minus 198291 average; Fig. 8) during each summer month divided by the global mean surface temperature $\left(T_{S}\right)$ change over the same time period. We use two different observationally based datasets to calculate the change in surface albedo over this time period: 1) sea ice concentration calculated by the National Snow and Ice Data Center (Cavalieri et al. 1996) from passive microwave brightness measured by the Nimbus-7 satellite available from 1979 to 2016 and 2) broadband (all-sky) surface albedo measured by the Advanced Very High Resolution Radiometer (AVHRR) Polar Pathfinder (APP-x) extended dataset (Wang and Key 2005) that covers the 1982-2017 time period. The central estimate of our observationally based IS is the average of calculations from these two datasets (elaborated on below) and our uncertainty estimates account for differences across the two datasets.

The NSIDC sea ice concentration changes are converted to a surface albedo change record by multiplying the SIC changes by the albedo contrast between sea ice and open ocean $(\Delta \alpha)$, which is assumed to be spatially and temporally invariant:

$$
\mathrm{IS}=\frac{d \mathrm{SIC}}{\left[d T_{S}\right]} \Delta \alpha .
$$

Equation (5) assumes that changes in $\alpha_{\text {SI }}$ are isolated to regions of sea ice melt. NSIDC monthly maps of the decadal average change in sea ice concentration are multiplied by an assumed surface albedo contrast between the open ocean and sea ice $(\Delta \alpha)$ of 0.54 , assuming a typical ice $\alpha$ of 0.6 (Hummel and Reck 1979) and an ocean albedo of 0.06 (Hansen et al. 1983). This choice of typical ice albedo is an average of snowcovered sea ice found during the late spring and sea ice with melt ponds in the late summer (see Fig. 9 of Perovich et al. 2002). This map of monthly NSIDC iceconcentration-derived surface albedo change and those derived from the APP-x (also monthly) data are averaged to produce the observational best estimate of change in surface albedo (Fig. 8c), hereafter referred to as the observational best estimate (OBE). Both products produce similar estimates of surface albedo changes (see Fig. A4 in the appendix). We use differences between the two surface albedo datasets as well as the intradecadal variability within each dataset to calculate the uncertainty in observational IS (Fig. 8d) as outlined in the appendix.

Observational IS is calculated by normalizing OBE surface albedo changes by a global surface temperature change of $0.7 \pm 0.1 \mathrm{~K}$ over the 1982-2016 time period. The central estimate and uncertainty in global mean surface temperature change come from the average and standard deviation of the mean across three different global surface temperature datasets: 1) the National Centers for Environment Prediction (NCEP) reanalysis surface air temperature (Kalnay et al. 1996), 2) the Goddard Institute for Space Studies Surface Temperature Analysis (GISTEMP) (Hansen et al. 1999), and 3 ) the modification by Cowtan and Way (Cowtan and Way 2014) of the Met Office Hadley Centre surface temperature dataset (Morice et al. 2012) version 4 (HadCRUT4).

The monthly IS is then multiplied by the monthly RS derived from CERES data, and then time averaged (over the summer months) to produce a map of radiative impact of sea ice changes (Fig. 8e). While the previous figures showed MJJA average in the $\mathrm{NH}$ and NDJF in the SH, Fig. 8e extends the summertime season to include the six months centered on the summer solstice [April-September (AMJJAS) in NH and OctoberMarch (ONDJFM) in the $\mathrm{SH}$ ] since previous work (Flanner et al. 2011) found an appreciable contribution 
Radiative sensitivity

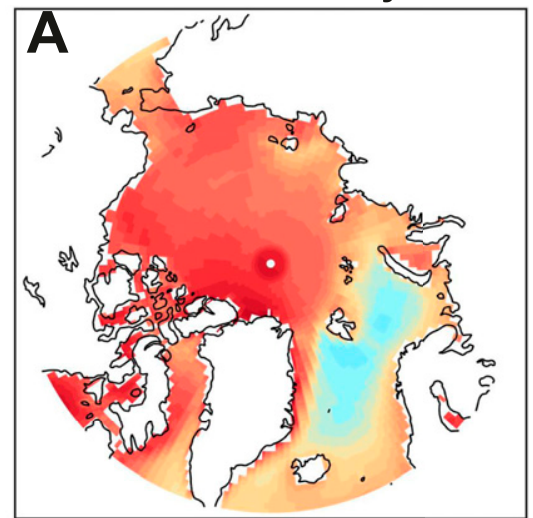

$\mathrm{W} \mathrm{m}^{-2}$ into system per 0.01 albedo decrease

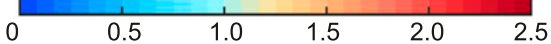

\section{Observed Ice sensitivity}

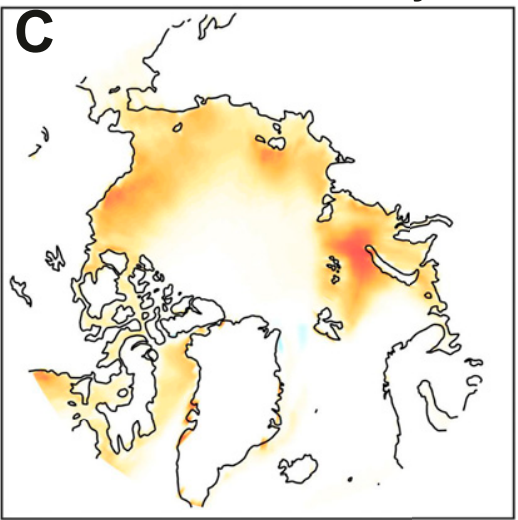

Ice sensitivity -- Albedo change per $\mathrm{K}$

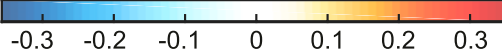

Radiative Impact of Albedo

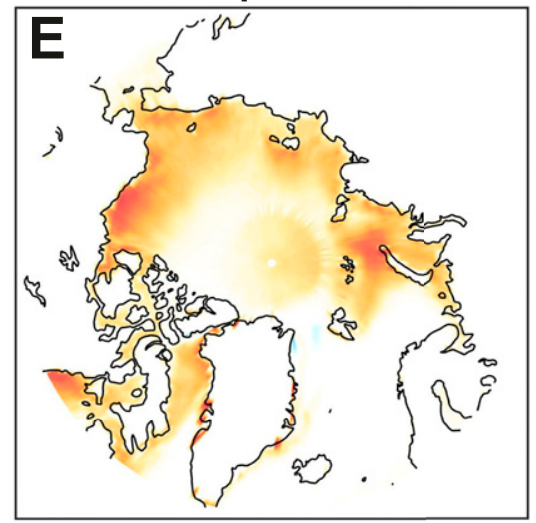

Radiative Impact $\left(\mathrm{W} \mathrm{m} \mathrm{m}^{-2} \mathrm{~K}^{-1}\right)$

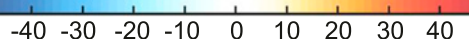

Uncertainty in Radiative sensitivity

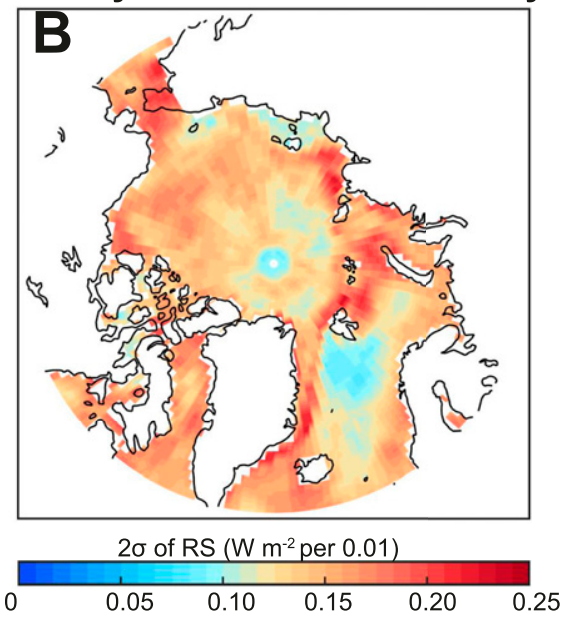

\section{Uncertainty in Ice Sensitivity}

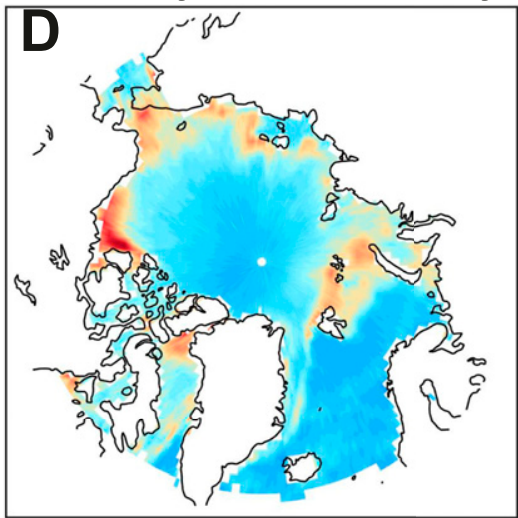

$2 \sigma$ Ice sensitivity (albedo per K)

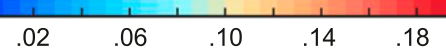

Uncertainty in Radiative Impact

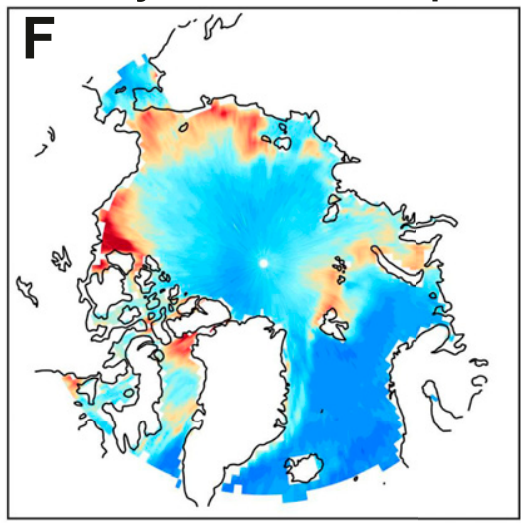

$2 \sigma$ Radiative Impact $\left(\mathrm{W} \mathrm{m}^{-2} \mathrm{~K}^{-1}\right)$

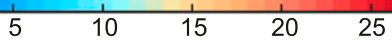

FIG. 8. Spatial maps of observational estimates of summertime (MJJA) (top) radiative sensitivity (RS) and (middle) ice sensitivity (IS), and (bottom) the radiative impact of surface albedo change $\left(\mathrm{RI}_{\mathrm{TOA}, \alpha}\right)$. The RS is calculated from the isotropic shortwave model applied to the CERES data. The IS is calculated from observational best estimate (OBE) surface albedo change between 1982 and 2016 divided by the global mean surface temperature change. (left) The central estimates of each quantity and (right) the uncertainty ( 2 standard deviations, $\sigma$ ) calculated from a Monte Carlo bootstrapping resampling with replacement as described in the appendix. 
to the SIAF during the shoulder seasons especially in April. The uncertainty in the $\mathrm{RI}_{\mathrm{TOA}, \alpha}$ (Fig. 8f) is assessed from a Monte Carlo simulation that takes into account three different uncertainties in the input datasets propagated (in quadrature) onto the calculation of $\mathrm{RI}_{\mathrm{TOA}, \alpha}$ (see the appendix for details): 1) the uncertainty in RS, due to uncertainty in the climatological radiative fluxes; 2) uncertainty in the surface albedo change, due to both intradecadal variability and differences between the APP-x and NSIDC ice concentrations datasets; and 3) uncertainty in the global mean temperature change that goes into the calculation of IS. We note that $\mathrm{RI}_{\mathrm{TOA}, \alpha}$ in Fig. $8 \mathrm{e}$ is, by definition, the radiative impact of sea ice changes normalized by global mean surface temperature change $(=0.7 \mathrm{~K})$ and has a summertime (AMJJAS) Arctic domain average of $4.9 \pm$ $1.4 \mathrm{~W} \mathrm{~m}^{-2} \mathrm{~K}^{-1}$, which translates to an absolute change in summertime radiation of $3.4 \pm 1.0 \mathrm{~W} \mathrm{~m}^{-2}$ over the Arctic. To convert this number to a global and annual mean radiative impact, one must weight this number by the ratio of summer months to the year (6/12) and the spatial area of the Arctic (poleward of $60^{\circ} \mathrm{N}$ ) divided by that of the globe (0.065), resulting in a global TOA radiative change of $0.11 \mathrm{~W} \mathrm{~m}^{-2}$ over the 1982-2016 period. This translates to a global radiative feedback (divide by $0.7 \mathrm{~K}$ global $T_{S}$ change) of $0.16 \pm 0.04 \mathrm{~W} \mathrm{~m}^{-2} \mathrm{~K}^{-1}$ given the observed global surface temperature change over the same period. The uncertainties cited above reflect 2 standard deviations.

We do not estimate the observationally based surface albedo feedback in the SO because the change in SO sea ice concentration over the observational period is not statistically significant above the year-to-year variability (Jones et al. 2016). We also note that this estimate is isolated to the Arctic Ocean (we have masked the APP-x albedo changes over land) and, thus, does not include the impact of changes in snow cover over land.

\section{Comparison of observational and model SIAF and decomposition of intermodel spread of SIAF into $R S$ and IS}

We now compare the observational Arctic SIAF derived above with that derived by the same methodology in historical CMIP5 simulations. The RS for each climate model that was calculated using the isotropic model in the previous section (from the climatology at end of the historical simulation, 1995 to 2005) is multiplied by the decadal average surface albedo change, calculated as the ratio of upwelling to downwelling broadband shortwave radiation at the surface, over the historical simulation (1995 to 2005 minus 1975 to 1985). We note that this time period was chosen to correspond to the end of the historical simulations and differs from the 1982 to 2016 period used for the observational calculations. The RS and surface albedo changes are calculated for each month and the product is spatially averaged over the Arctic Ocean to calculate the SIAF; we exclude the impact of changes in snow cover over land from our calculations. For simplicity, we will only discuss the annual and global mean of the calculations normalized by the global mean surface temperature change over the same time period, as we did for the observations. The CMIP5 ensemble mean Arctic SIAF in the historical simulations is $0.12 \mathrm{~W} \mathrm{~m}^{-2} \mathrm{~K}^{-1}$ with a spread ( 2 standard deviations, $\sigma$ ) of $0.13 \mathrm{~W} \mathrm{~m}^{-2} \mathrm{~K}^{-1}$ (gray histogram in Fig. 9a with wide bars). The ensemble mean is slightly smaller than the observational estimate (cf. the solid and dashed vertical black lines in Fig. 9) but the large intermodel spread indicates that the models differ in either RS and/or IS. We now ask how much RS and IS contribute to the intermodel differences in Arctic SIAF.

To estimate the IS contribution to the SIAF spread, the calculation of SIAF is repeated but the model specific RS is replaced with the observationally based RS value. The resulting distribution of SIAF (blue histogram in Fig. 9a) shows the spread produced by biases and intermodel differences in IS. The mean value of SIAF in the fixed RS distribution $\left(0.12 \mathrm{~W} \mathrm{~m}^{-2} \mathrm{~K}^{-1}\right.$; Table 1) is nearly equal to that of the full SIAF calculation (cf. the blue and black vertical lines). The CMIP5 ensemble average SIAF is quite insensitive to RS model biases, and it is lower than the observed estimate because the modeled IS is smaller than the observational estimate. Furthermore, the spread in the fixed RS distribution is only slightly smaller than that of the full SIAF calculation $\left(2 \sigma=0.12 \mathrm{~W} \mathrm{~m}^{-2} \mathrm{~K}^{-1}\right)$, indicating that the majority of the intermodel spread in SIAF calculated from the historical simulation is a result of the IS differences between models.

A similar analysis can be made to estimate the impact of biases (relative to observations) and intermodel RS differences on the calculated SIAF by replacing the model specific IS with that derived from observations (red histogram in Fig. 9a). The CMIP5 ensemble average SIAF of the fixed IS distribution $\left(0.16 \mathrm{~W} \mathrm{~m}^{-2} \mathrm{~K}^{-1}\right.$; Table 1) is larger than that of the full SIAF calculation (cf. the red and black vertical lines in Fig. 9), indicating that the CMIP5 ensemble average IS is smaller than that observed (the OBE value), a result also found by Rosenblum and Eisenman (2016). The intermodel spread in SIAF in the fixed IS experiment $\left(2 \sigma=0.04 \mathrm{~W} \mathrm{~m}^{-2} \mathrm{~K}^{-1}\right)$ is smaller than that of the full calculation and fixed RS experiment, indicating that intermodel differences in RS play a smaller but not 
A Arctic -- Historical Simulation

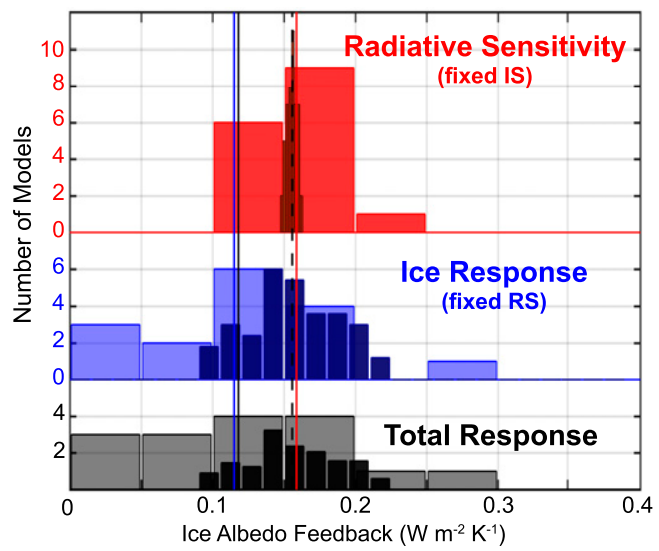

B

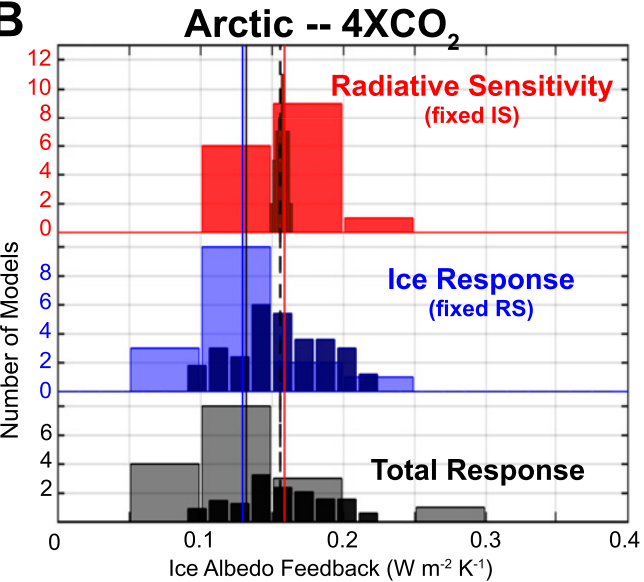

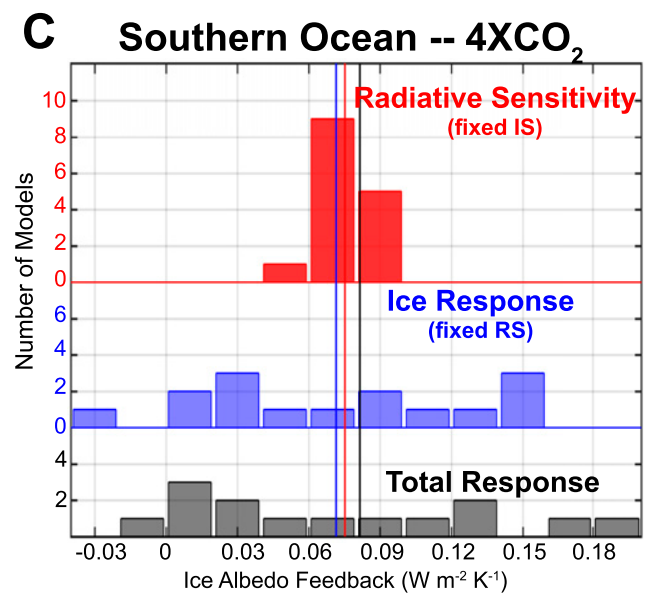

FIG. 9. Estimates of global (and annual) SIAF from climate models and observations using the radiative sensitivity (RS) from the isotropic model applied to the climatology and the change in surface albedo under external forcing normalized by the global mean temperature change. (a) Arctic sea ice changes over the historical (2007-16 minus 1982-91 averages). The black bars show the CMIP5 model distribution using the climate model specific radiative sensitivity and ice changes, the blue bars show the distribution using the model specific sea ice changes and observational RS, and the red bars show the distribution using the observational sea ice change and model specific radiative sensitivity. Solid vertical lines show the model mean of each distribution. The dashed vertical line shows the observational estimate. The overlaid dark and thinner distribution shows the histogram of observational estimates of ice albedo feedback calculated from a Monte Carlo resampling of subsets of the ice albedo data and radiative data; the black distribution shows the impact of uncertainties in the observational RS and IS combined, the blue distribution shows the impact of the IS uncertainty only, and the red shows the impact of the RS uncertainty only. (b) As in (a), but using the modeled changes in the $4 \times \mathrm{CO}_{2}$ simulations. (c) Distribution of surface albedo feedback in the Southern Ocean diagnosed from $4 \times \mathrm{CO}_{2}$ normalized sea ice changes. Because the observational estimate of sea ice changes over the historical simulation is not statistically significant, the red distribution is calculated from the model specific radiative sensitivity and the model mean normalized sea ice change.

insignificant role in the SIAF spread calculated over the historical simulations. A summary of the role of biases and intermodel differences in RS and IS in determining the model distribution of SIAF is provided in Table 1.

This partitioning of SIAF differences in contributions from RS and IS takes spatial and temporal covariances of ice loss and RS into account by weighting the ice loss to the RS at that location and time. Similar results for the impact of IS and RS on the total spread in SIAF are obtained by simply noting the fractional spread (relative to the ensemble mean) of summertime Arctic domain average RS and IS between models. The ratio of domain and summertime average intermodel spread $(2 \sigma)$ to the ensemble mean domain and summertime average of $\mathrm{RS}$ is $40 \%$ whereas that of IS is $107 \%$, roughly scaling with the fractional contribution to SIAF spread calculated above. This result suggests that 
TABLE 1. SIAF values (in $\mathrm{W} \mathrm{m}^{-2} \mathrm{~K}^{-1}$ ) for the (top) Arctic and (bottom) Southern Ocean derived from (left) observations and model simulations of (middle) $4 \times \mathrm{CO}_{2}$ and (right) historical simulations. Each value shows the central estimate and $2 \sigma$ range across the bootstrapping Monte Carlo simulations for the observations and intermodel spread for the models. The top row in each hemisphere shows the full calculation using the model specific RS and IS. The second row shows the impact of intermodel differences in IS as calculated using the model specific IS and the observed RS. The third row shows the impact of intermodel differences in RS as calculated using the model specific RS and the observed IS.

\begin{tabular}{|c|c|c|c|}
\hline \multicolumn{4}{|c|}{ Arctic } \\
\hline & Observations & $4 \times \mathrm{CO}_{2}$ & Historical \\
\hline Full calculation & $0.16 \pm 0.04$ & $0.13 \pm 0.09$ & $0.12 \pm 0.13$ \\
\hline $\begin{array}{c}\text { IS contribution } \\
\mathrm{RS}_{\mathrm{OBS}} \times \text { IS }\end{array}$ & & $0.13 \pm 0.08$ & $0.12 \pm 0.12$ \\
\hline RS contribution & & $0.16 \pm 0.04$ & $0.16 \pm 0.04$ \\
\hline \multicolumn{4}{|c|}{ Southern Ocean } \\
\hline & Observations & $4 \times \mathrm{CO}_{2}$ & Historical \\
\hline Full calculation & & $0.08 \pm 0.13$ & \\
\hline $\begin{array}{c}\text { IS contribution } \\
\mathrm{RS}_{\mathrm{OBS}} \times \text { IS }\end{array}$ & & $0.07 \pm 0.11$ & \\
\hline $\begin{array}{c}\text { RS contribution } \\
\text { RS } \times \text { IS }_{\text {OBS }}\end{array}$ & & $0.08 \pm 0.04$ & \\
\hline
\end{tabular}

intermodel differences in IS and RS are fairly spatially and temporally homogenous and the resultant intermodel spread in SIAF is independent of the spatiotemporal covariability of RS and IS. Previous work has found similar large-magnitude intermodel spread in IS in CMIP3 (Mahlstein and Knutti 2012) and CMIP5 (Stroeve and Notz 2015) linked to the spread in the magnitude of Arctic amplification.

The sea ice retreat over the historical record represents the superposition of the response to climate forcing and natural variability and, thus, the intermodel spread in IS calculated over the 30 years of historical simulations is expected to exceed that in response to long-term sustained forcing. Schneider et al. (2018) found that decadal trends in sea ice during periods when global mean temperatures increased by more than $0.5 \mathrm{~K}$ provided good estimates of the long-term SIAF in an ensemble of climate models. Other studies suggest that as much as $50 \%$ of the observed Arctic sea loss since 1979 could be a result of the natural variability of atmospheric circulation (Ding et al. 2017, 2019; Kay et al. 2011). To reduce the amount of internal variability relative to the forced component, we also look at the contribution of RS and IS to the intermodel spread in SIAF in response to an abrupt and sustained quadrupling of atmospheric $\mathrm{CO}_{2}$ where the forced climate change signal is expected to be larger than the natural variability. The IS in the $\mathrm{CO}_{2}$ quadrupling simulations is calculated from the change in surface albedo and global mean surface temperature between the PI and the average over years 50-100 since $\mathrm{CO}_{2}$ quadrupling. The RS used to calculate the SIAF is calculated from the PI climatological fields in the same model. The ensemble average Arctic SIAF calculated from the $4 \times \mathrm{CO}_{2}$ simulations is $0.13 \pm 0.09 \mathrm{~W} \mathrm{~m}^{-2} \mathrm{~K}^{-1}$ (uncertainty is $2 \sigma$ ) and is in close agreement with the ensemble average of the historical simulation $\left(0.12 \pm 0.13 \mathrm{~W} \mathrm{~m}^{-2} \mathrm{~K}^{-1}\right)$ with reduced intermodel spread. The central estimate and range of SIAF from all model simulations-calculated from $2 \sigma$ of the mean-is $0.13 \pm 0.02 \mathrm{~W} \mathrm{~m}^{-2} \mathrm{~K}^{-1}$ and is slightly smaller than but not statistically different from the observational estimate $\left(0.16 \pm 0.04 \mathrm{~W} \mathrm{~m}^{-2} \mathrm{~K}^{-1}\right)$. Because the $4 \times \mathrm{CO}_{2}$ ice response primarily reflects the forced response, the similarity of the ensemble average SIAF diagnosed from historical and $4 \times \mathrm{CO}_{2}$ simulations suggests that the same physics responsible for the long-term SIAF are evident in historical simulations despite the additional statistical noise from internal variability.

When the model-specific RS is replaced by the observational estimate of RS the resultant Arctic SIAF for the $\mathrm{CO}_{2}$ quadrupling simulations is $0.13 \pm 0.08 \mathrm{~W} \mathrm{~m}^{-2} \mathrm{~K}^{-1}$ and when the model-specific IS is replaced by the observational estimate of IS the resultant SIAF is $0.16 \pm$ $0.04 \mathrm{~W} \mathrm{~m}^{-2} \mathrm{~K}^{-1}$ (lower left panel of Fig. 9 and Table 1). These results suggest that in the long-term response to sustained anthropogenic forcing 1) the CMIP5 ensemble average RS (spatially and temporally weighted by the relevant regions of ice loss) is very near the observational estimate, 2) the CMIP5 ensemble average IS (spatially and temporally weighted by structure of RS) is slightly smaller than the observational estimate and is responsible for the model SIAF being smaller than the observational estimate and 3) intermodel differences in IS contribute twice as much to the intermodel spread in SIAF ( $63 \%$ of the ensemble average value) as do intermodel differences in RS $30 \%$ of the ensemble average value). We note that the intermodel spreads in IS and RS are significantly $(R=0.54)$ correlated (at $95 \%$ confidence interval) and we return to the implications of this result in the discussion section.

A similar analysis can be performed for the $4 \times \mathrm{CO}_{2}$ simulations in the SO (poleward of $55^{\circ} \mathrm{S}$ ) to indicate an ensemble average SIAF of $0.08 \pm 0.13 \mathrm{~W} \mathrm{~m}^{-2} \mathrm{~K}^{-1}$ (Fig. 9c, Table 1). The SO SIAF is negative in a single model (GFDL ESM2G) that simulates sea ice growth in the Weddell Sea under $4 \times \mathrm{CO}_{2}$. When the modelspecific RS is replaced by the observational estimate of $\mathrm{RS}$, the calculated SO SIAF is $0.07 \pm 0.11 \mathrm{~W} \mathrm{~m}^{-2} \mathrm{~K}^{-1}$, suggesting the the ensemble average RS is slightly larger than that estimated from the observations, 
consistent with Fig. 7. Because no observational estimate of SO IS is available, we probe the sensitivity of SO SIAF to RS by replacing the model-specific IS with the ensemble average IS, resulting in a calculated SIAF of $0.08 \pm 0.04 \mathrm{~W} \mathrm{~m}^{-2} \mathrm{~K}^{-1}$; intermodel differences in RS result in intermodel differences in SO SIAF of magnitude $50 \%$ the ensemble mean estimate. However, the contribution of intermodel spread in RS to SIAF spread is dwarfed by the impact of intermodel differences in IS, which produces intermodel differences in SO SIAF exceeding the central estimate by almost a factor of $1.5(160 \%)$. This result is consistent with the large intermodel differences in SO ice response to global warming reported by Shu et al. (2015) and Polvani and Smith (2013).

\section{Global surface albedo feedback: Comparison to IPCC AR5 value}

The IPCC AR5 estimated a global surface albedo feedback of $0.26 \mathrm{~W} \mathrm{~m}^{-2} \mathrm{~K}^{-1}$ based on the calculations of Soden and Held (2006), which use a single RS-derived fom kernel calculations in the GFDL model (Fig. 1)-applied the surface albedo change in each CMIP3 model. These calculations are global and include the impact of $\alpha$ changes over land (due to changes in snow cover) in addition to the sea ice related changes considered up to this point and we term this combined contribution of land and sea ice changes the global albedo feedback (GAF). More recently, Schneider et al. (2018) presented a CMIP5 ensemble mean GAF $0.40 \mathrm{~W} \mathrm{~m}^{-2} \mathrm{~K}^{-1}$ using NCAR CAM5-based kernels. It is unclear if this discrepancy results from the different RS used in these studies or the IS in different GCM ensembles. Here, we compare the GAF produced using the (kernel based) RS from a single model to that calculated using a model specific RS derived from the isotropic model.

Our GAF calculations are based upon surface albedo change calculated from the $4 \times \mathrm{CO}_{2}$ simulations minus that in the preindustrial simulation normalized by the global mean surface temperature (TS) change in that model-a quantity akin to IS in Eq. (2) but including the albedo changes over land. This albedo change is multiplied by RS estimated two ways: 1) using the method introduced in this study, where RS is calculated from the isotropic model [Eq. (4)] using radiative fluxes from appropriate model-specific preindustrial simulation and 2) using the method introduced by Soden and Held (2006) where the GFDL surface albedo kernel (Fig. 1) is used to estimate RS for all models. We separate the GAF calculation into hemispheres. In the $\mathrm{NH}$, the GAF calculated in this study is larger than that calculated using the GFDL kernel in all models (all the red dots fall below the 1:1 line in the upper left panel of Fig. 10) as would be expected from the GFDL RS being at the very low end of the model range, especially over the ocean domain. In the CMIP5 ensemble average, the NH GAF is $0.20 \mathrm{~W} \mathrm{~m}^{-2} \mathrm{~K}^{-1}$ using the GFDL kernel as compared to $0.27 \mathrm{~W} \mathrm{~m}^{-2} \mathrm{~K}^{-1}$ using the isotropic model methodology (35\% greater; Table 2). The NH GAF has $64 \%$ more spread using the model-specific RS because 1) the ensemble mean RS is larger than the GFDL kernel RS and 2) the intermodel spread in RS contributes to the GAF spread as discussed in the previous subsection. If we restrict the calculation to the Arctic Ocean poleward of $60^{\circ} \mathrm{N}$ (as was done in sections 4 and 5) we find a CMIP5 ensemble average SIAF of $0.09 \mathrm{~W} \mathrm{~m}^{-2} \mathrm{~K}^{-1}$ using the GFDL kernel compared to the $0.13 \mathrm{~W} \mathrm{~m}^{-2} \mathrm{~K}^{-1}$ (Table 1) using the isotropic model methodology $(45 \%$ greater). This result suggests that approximately half of the GAF is due to $\alpha$ changes over land as found by Flanner et al. (2011).

In the Southern Hemisphere, the GAF estimates from the two methods are in closer agreement; the dots cluster along near the 1:1 line in the upper right panel of Fig. 10 with the exception of the models producing the highest GAF. This result is expected since the GFDL RS is near the ensemble mean over the SO (Figs. 2 and 7). The ensemble average GAF in the $\mathrm{SH}$ is, therefore, very similar when using the methodology in this study $\left(0.09 \mathrm{~W} \mathrm{~m}^{-2} \mathrm{~K}^{-1}\right)$ as compared to that calculated using GFDL RS only $\left(0.08 \mathrm{~W} \mathrm{~m}^{-2} \mathrm{~K}^{-1}\right.$; Table 2$)$. Globally, we calculate a GAF of $0.37 \mathrm{~W} \mathrm{~m}^{-2} \mathrm{~K}^{-1}$, which is $30 \%$ greater than the same result found applying the GFDL RS to CMIP5 $4 \times \mathrm{CO}_{2}$ simulations of $0.29 \mathrm{~W} \mathrm{~m}^{-2} \mathrm{~K}^{-1}$. We note the the IPCC AR5 cites a global GAF of $0.26 \mathrm{~W} \mathrm{~m}^{-2} \mathrm{~K}^{-1}$ derived from the GFDL kernel and CMIP4 simulations and, thus, our estimate is $40 \%$ larger than the AR5 value. We attribute $30 \%$ of this increase to improved methodology of using modelspecific RS and $10 \%$ to the difference between CMIP4 and CMIP5 model characteristics. Importantly, the IPCC diagnosis of the overall climate sensitivity of climate models is unaffected by our revised more positive GAF. Rather, our results suggest that the shortwave cloud feedback should be revised downward by the same amount because cloud feedbacks are diagnosed from all-sky minus clear-sky TOA radiation adjusted by all-sky minus clear-sky radiative kernel calculations.

\section{Summary and discussion}

We have shown that the radiative impact of surface albedo changes [radiative sensitivity (RS)] calculated 

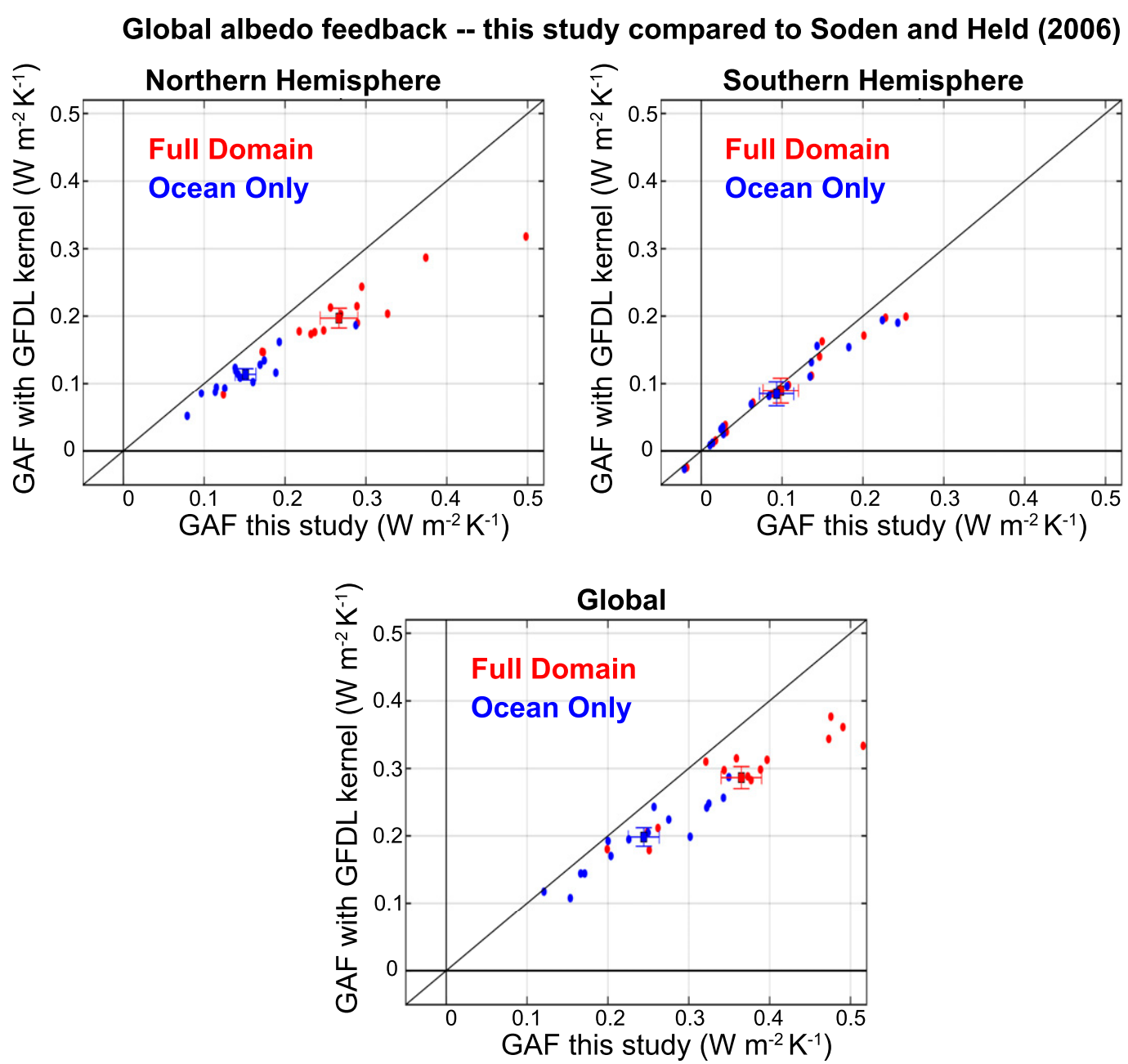

FIG. 10. Comparison of ice albedo feedback calculated from CMIP5 $4 \times \mathrm{CO}_{2}$ using (ordinate) the method of Soden and Held (2006b) with RS in all models set to the GFDL surface albedo kernel vs (abscissa) the method introduced here with RS calculated from the model specific climatological radiative fluxes via the isotropic model. The blue markers show the contribution of the ocean domain only and the red markers show the full domain. All values shown are the contribution to the global mean. Dots show individual models and filled squares show the ensemble average with bars showing one standard deviation of the mean. (top left) NH, (top right) SH, and (bottom) the global mean. The black line is the 1:1 line.

using offline radiative transfer models (radiative kernels) can be closely replicated using a single-layer isotropic SW radiation model applied to the climatological radiative fluxes at the TOA and surface. This procedure allows estimates of SIAF to be conveniently calculated from observational datasets and standard model output without use of a kernel calculation, facilitating a comparison of observational and model estimates of SIAF. It also allows the differences between models and observation-based calculations to be decomposed into contributions from RS and IS. The multimodel mean of $\mathrm{RS}$ is close to the observational estimate in the Arctic and only slightly larger than the observational estimate in the Southern Ocean (SO). However, the intermodel spread in RS (Figs. 6 and 7) is substantial, producing intermodel differences in SIAF estimates that are $30 \%$ and $50 \%$ the magnitude of the ensemble mean SIAF in the Arctic and SO respectively. In agreement with Sledd and L'Ecuyer (2019), high-latitude clouds tend to mask the impact of surface albedo variations on the TOA albedo by a factor of 2-3 in observational estimates. Differences in climate model clouds influence the degree of cloud masking.

Our results indicate that intermodel differences in IS are more important than RS in explaining the intermodel spread in SIAF. However, IS is not statistically independent of RS $(R=0.54)$. It is possible that intermodel differences in RS contribute to intermodel 
TABLE 2. Global albedo feedback (GAF) in CMIP5 climate models calculated using the methodology of this study-with a model-specific RS from the isotropic model-compared to that calculated using RS from the GFDL surface albedo kernel for all models. The CMIP5 ensemble mean and $2 \sigma$ are shown for each hemisphere and divided into ocean and full domains.

\begin{tabular}{lcc}
\hline \hline & Northern Hemisphere & \\
\hline & Ocean domain & Total \\
\hline This study & $0.15 \pm 0.10$ & $0.27 \pm 0.18$ \\
GFDL RS kernel & $0.11 \pm 0.06$ & $0.20 \pm 0.11$ \\
& Southern Hemisphere & \\
\hline & Ocean domain & Total \\
\hline This study & $0.09 \pm 0.16$ & $0.10 \pm 0.17$ \\
GFDL RS kernel & $0.08 \pm 0.14$ & $0.09 \pm 0.15$ \\
& Global & \\
\hline This study & Ocean domain & Total \\
GFDL RS kernel & $0.24 \pm 0.15$ & $0.37 \pm 0.19$ \\
\hline
\end{tabular}

difference in IS because models that have a larger radiative response to sea ice loss will tend to have greater sea ice loss due to a stronger positive feedback between initial ice loss and radiative heating. In this sense, the contribution of RS to intermodel differences in SIAF of $0.04 \mathrm{~W} \mathrm{~m}^{-2} \mathrm{~K}^{-1}$ both in the Arctic and $\mathrm{SO}$ can be thought of as a lower bound on the contribution of mean state radiative biases to the SIAF. We hope to explore the impact of mean state radiative biases (RS) on IS and the persistence of sea ice loss events in future work.

We estimate an observationally based global, and annually averaged increase in TOA radiation of $0.11 \mathrm{~W} \mathrm{~m}^{-2}$ from Arctic sea ice changes over the 1982 2016 time period using observationally based estimates of sea ice changes and the CERES-derived radiative sensitivity implying a SIAF of $0.16 \pm 0.04 \mathrm{~W} \mathrm{~m}^{-2} \mathrm{~K}^{-1}$. Flanner et al. (2011) found a Northern Hemisphere average "crypospheric radiative forcing" of $0.45 \mathrm{~W} \mathrm{~m}^{-2}$ over the 1979-2008 time period, about half of which $\left(0.22 \mathrm{~W} \mathrm{~m}^{-2}\right)$ was attributed to sea ice changes while the other half was attributed to snow changes over land. Thus, the Flanner et al. (2011) result converted to a global average $\left(0.22 / 2=0.11 \mathrm{~W} \mathrm{~m}^{-2}\right)$ agrees very well with our findings. Similarly, Cao et al. (2015) found a Northern Hemisphere SIAF of $0.25 \mathrm{~W} \mathrm{~m}^{-2} \mathrm{~K}^{-1}$ using observed surface albedo change and RS estimated using model-based kernels derived from GFDL (Soden and Held 2006) and CAM3 (Shell et al. 2008). This result translates to a global feedback of Arctic changes of $0.12 \mathrm{~W} \mathrm{~m}^{-2} \mathrm{~K}^{-1}$, which is smaller than our central estimate and we speculate this result follows from the lower than observed RS in the CAM3 kernel (Fig. 1).
Pistone et al. $(2014,2019)$ calculated a substantially larger SIAF $\left(0.31 \pm 0.04 \mathrm{~W} \mathrm{~m}^{-2} \mathrm{~K}^{-1}\right)$ from the interannual covariance of sea ice concentration and TOA radiation measured by CERES. We speculate that some of the TOA radiative variability that coincides with ice loss events in Pistone et al. (2014) is not directly a consequence of (i.e., geographically collocated with and/ or a radiative consequence) surface albedo changes but, rather, is a consequence of atmospheric optical properties (i.e., clouds, water vapor, etc) that covary with Arctic sea ice concentration. A central question moving forward is whether the atmospheric changes (and the associated radiative anomalies) accompanying Arctic sea ice loss over the limited historical period result from natural variability of atmospheric circulation initiated by tropical and midlatitude processes or are a direct result of sea ice loss and, thus, should be expected to also apply to future climatological changes. Additionally, how accurately does the observational IS calculated over the historic record represent the expected relationship between future changes in Arctic ice concentration and global mean temperature?

Pistone et al. (2014) suggest that the SIAF (Arctic Ocean only) alone results in a $25 \%$ enhancement of global warming via radiative feedbacks, a value they derive from the ratio of their calculated radiative impact of historic ice loss divided by the anthropogenic climate forcing to date. We offer two modifications as updates to their calculation: 1) a significantly lower estimate of the radiative impact of Arctic sea ice loss outlined above and 2) consideration of how the implied feedback relates to equilibrium climate sensitivity, noting that the climate system is not currently in equilibrium with the anthropogenic forcing to date. For the latter reason, the feedback gain of the Arctic SIAF should be calculated by comparing the SIAF to the equilibrium radiative feedback of all other radiative processes as opposed to the ratio of the transient radiative impact of ice loss to date to the applied forcing. Given observational central estimates of the total equilibrium feedback parameter of $-1.19 \mathrm{~W} \mathrm{~m}^{-2} \mathrm{~K}^{-1}$ (Armour 2017) and our observational estimate of the Arctic SIAF $\left(\lambda_{\mathrm{SLAF}}=+0.16 \pm\right.$ $0.04 \mathrm{~W} \mathrm{~m}^{-2} \mathrm{~K}^{-1}$ ), the implied feedback parameter of all processes excluding the SIAF $\left(\lambda_{0}\right)$ satisfies the equation $-1.19 \mathrm{~W} \mathrm{~m}^{-2} \mathrm{~K}^{-1}=\lambda_{0}+0.16 \mathrm{~W} \mathrm{~m}^{-2} \mathrm{~K}^{-1}$. This implies that $\lambda_{0}$ (the reference climate feedback parameter of a system with no SIAF) is $-1.35 \mathrm{~W} \mathrm{~m}^{-2} \mathrm{~K}^{-1}$. We note that the reference climate feedback parameter is more negative than that of a system with a SIAF, implying a smaller climate sensitivity of the reference system relative to the full system with a SIAF as is expected for the positive SIAF. The fractional amplification of global mean temperature changes-the 
feedback gain, $\mathrm{G}_{\mathrm{SIAF}}$-due to the SIAF is then (Roe 2009)

$$
G_{\mathrm{SIAF}}=\frac{1}{1+\frac{\lambda_{\mathrm{SIAF}}}{\lambda_{0}}}=1.14 \pm .04 .
$$

Thus, our analysis suggests that the Arctic SIAF amplifies global warming by $14 \%$ ( $2 \sigma$ range between $10 \%$ and $19 \%$ ) at the equilibrium time scale and is a more modest amplifier of global warming than the $25 \%$ suggested by Pistone et al. (2014).

The IPCC AR5 report (Flato et al. 2013) points out a discrepancy between the observationally based SIAF of Flanner et al. (2011) and the model-based estimate of Soden and Held (2006) and speculates that models are biased toward low IS, but the roles of intermodel spread and biases in RS were neglected. While we find no ensemble mean model bias in Arctic RS (Fig. 6), the model estimate of RS used in Soden and Held (2006) is taken from radiative kernel calculations in a single (GFDL) model and then applied to the IS across models. The RS from that model (Fig. 1) is biased low relative to both the observationally based RS (by $46 \%$ of the kernel RS in the Arctic average) and the CMIP5 ensemble mean. As a result, the AR5 estimate of the global surface albedo feedback of $0.26 \mathrm{~W} \mathrm{~m}^{-2} \mathrm{~K}^{-1}$ based on the calculations of Soden and Held (2006) is substantially lower than our calculated value of $0.37 \mathrm{~W} \mathrm{~m}^{-2} \mathrm{~K}^{-1}$, which uses model specific RS estimates. This result suggests that at least some part of the low model bias identified in the IPCC AR5 is a consequence of using a RS that is inconsistent with some climate models. We recommend using model-specific RS derived from the isotropic model as a better practice to applying radiative kernels across models. Additionally, our results identified no discernible model bias in the SIAF at least when considering like quantities over the Arctic Ocean domain.

Acknowledgments. We thank Karen Shell, Xianglei Huang, and four anonymous reviewers for thoughtful critique of an earlier version of this manuscript. We thank Angeline Pendergrass, Chris Smith, Ryan Kramer, Karen Shell, Brian Soden, Karen Block, Thorsten Mauritsen, and Michael Previdi for providing radiative kernel calculation and their assistance providing further clarification on the appropriate climatological radiation fields to use for isotropic model calculations. We also thank Jeff Key and Xuanji Wang for providing the NOAA AVHRR Polar Pathfinder data. This work was funded by a Department of energy mini grant to the HLES team at PNNL, the NSF Antarctic
Program Grant Number PLR 1643436, and the NOAA MAPP Grant eGC1\#A127135.

Data availability statement: All data used in this work are publicly available through phase 5 of the Coupled Model Intercomparison Project (CMIP5), National Aeronautics and Space Administration Langley Research Center websites. Radiative kernels are available from websites maintained by the University Corporation for Atmospheric Research, the Max-Planck Institute, Karen Shell at Oregon State University, Brian Soden, and Chris Smith at the University of Leeds. Please see citations within the data and methods section of this manuscript for more information.

\section{APPENDIX}

\section{Uncertainty Estimate in the Observational Calculation of the Sea Ice Albedo Feedback}

The RS calculated from radiative kernel calculations, the APRP isotropic model of Taylor et al. (2007) and the alternative isotropic model of Donohoe and Battisti (2011) are compared in Fig. A1. Figure A2 shows the correlation across Arctic grid points between radiative kernel-based RS and that calculated using the isotropic model (top panel) versus applying the radiative kernel derived from one climate model to a different climate model. The same analysis is repeated for the Southern Ocean in Fig. A3.

We describe the methodology used to calculate the uncertainty in our observational estimates of the RS, IS, and $\mathrm{RI}_{\mathrm{TOA}, \alpha}$ the spatial average of which gives the resultant SIAF [Eq. (1)]. We do so by first bootstrapping (random resampling with replacement) the original observational data into subsets half the temporal length of the original data to produce an ensemble of records. For example, in the CERES data used to calculate the RS, we produce an ensemble of radiative climatologies derived from random selections of 9 years of the 18 years of data. This procedure queries how sensitive the radiative climatologies are to the limited length of the CERES record. Similarly, the surface albedo changes are calculated from the difference of random selections of 5-yr averages within the period 1982-91 and 2007-16. We then use the resampled data to calculate the RS-using the isotropic model-and IS in a Monte Carlo simulation. We calculate 100 different estimates of RS and 100 different estimates of IS with 50 derived from resampled NSIDC ice concentration data and 50 derived from resampled APP-x data. Thus, our estimates of IS (Fig. 8d) account for two sources of uncertainty: 1) the impact of intradecadal variability on 


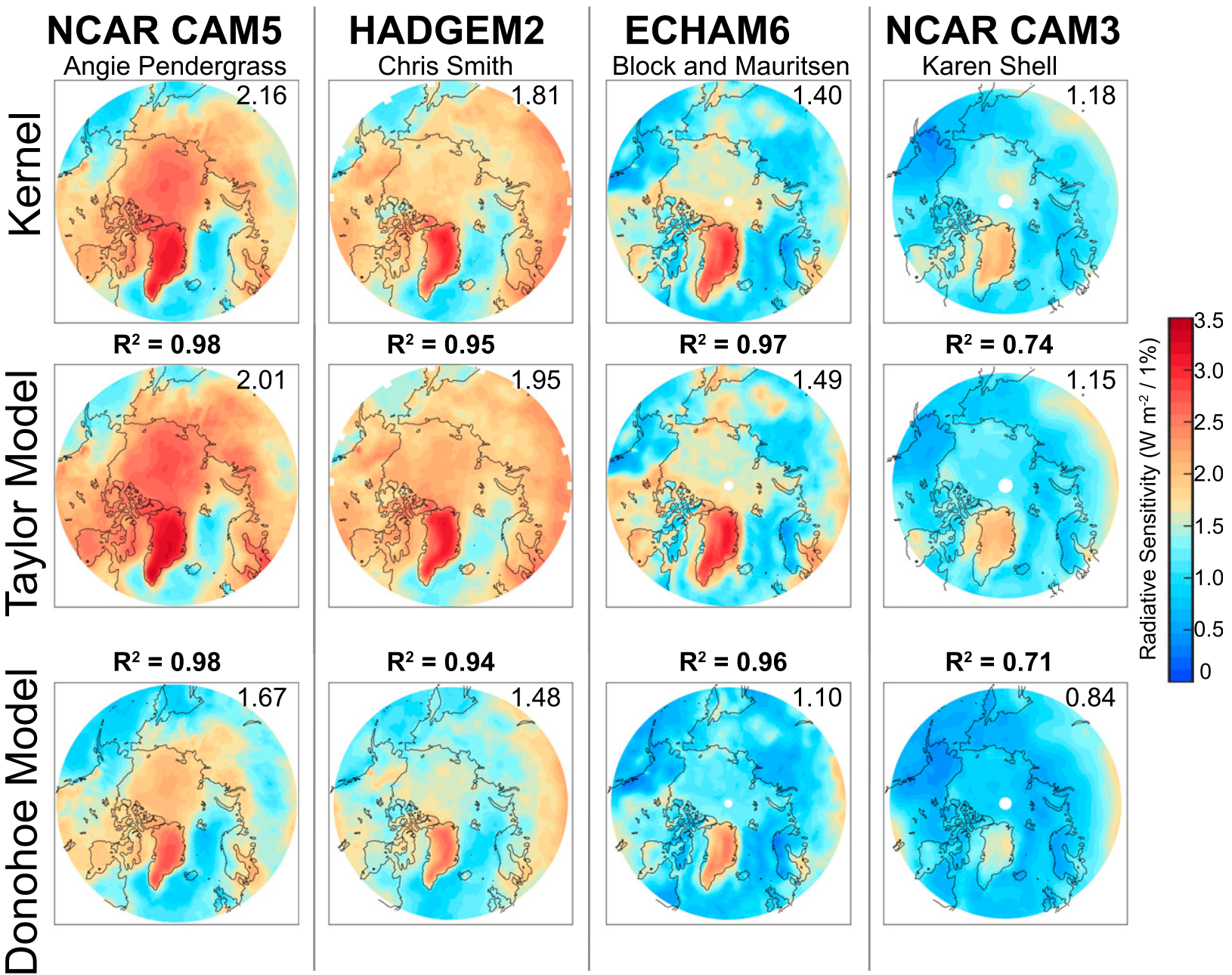

FIG. A1. Arctic summertime (MJJA) surface albedo radiative sensitivity (RS) (top) calculated from radiative kernels, and estimated from the climatological radiative fields using the idealized isotropic radiation model of (middle) T07 and (bottom) Donohoe and Battisti (2011) in the same models. The squared spatial correlation coefficients between the kernel isotropic methods in the same model are provided in the middle and the Arctic domain-averaged values are shown in the upper right of each panel.

calculating longer-term changes in surface albedo and 2) instrumental uncertainty.

The central estimates of surface albedo changes derived from the NSIDC and APP-x datasets are shown if Fig. A4. The within-dataset intradecadal variability of surface albedo contributes more to the IS uncertainty than the differences between APP-x and NSIDC sea ice concentration datasets; the standard deviation in IS calculated from ensembles of just the 50 NSIDC or 50 APP-x data is similar to that derived from the 100member ensemble considered collectively. Given that the NSIDC estimate of surface albedo change is derived from sea ice concentration changes only and does not account for changes in the albedo over ice, the similarity of the NSIDC and APP-x derived IS suggests that albedo changes are primarily associated with changes in ice area. The uncertainty in RS (taken as 2 standard deviations across the resampled ensemble) is approximately $10 \%$ of the mean RS with larger values in the vicinity of sea ice edge (Fig. 8b), suggesting that the cloud properties that determine the RS are fairly constant from year to year. In contrast, the uncertainty in the IS (Fig. 8d) is approximately $60 \%$ of the mean value with particularly large uncertainties in the Beaufort Sea, suggesting that the intradecadal variability and measurement uncertainty of sea ice changes substantially hinders the calculation of long-term IS over the relatively short observational record.

We now describe how we use the uncertainty in IS and RS to calculate the uncertainty in $\mathrm{RI}_{\mathrm{TOA}, \alpha}$, the 

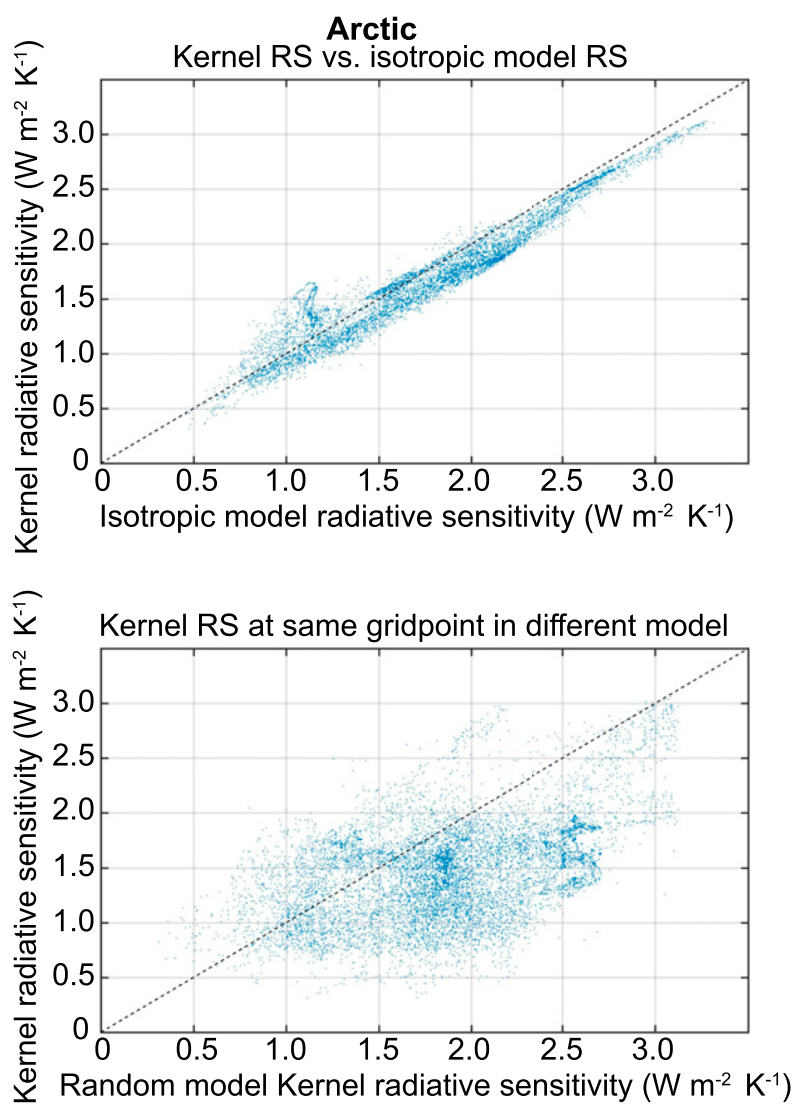

FIG. A2. (top) Scatterplot of MJJA radiative sensitivity calculated by (ordinate) radiative kernels and (abscissa) the isotropic model from the mean state in the same climate model. All four climate models and Arctic gridpoints considered collectively. (bottom) Scatterplot of MJJA radiative sensitivity calculated from radiative kernels in one model vs the radiative sensitivity calculated from radiative kernels in a different model (selected at random). The dashed black line shows the 1:1 line.

spatial average of which gives the SIAF uncertainty. We diagnose uncertainty $\mathrm{RI}_{\mathrm{TOA}, \alpha}$ by convoluting the 100 estimates of RS and the 100 estimates in IS to produce 10000 estimates of $\mathrm{RI}_{\mathrm{TOA}, \alpha}$. This procedure accounts for the spatial covariance of IS and RS uncertainty and central estimates. For example, the uncertainty in IS will have a larger impact in the regions and seasons where RS is largest. The uncertainty in the $\mathrm{RI}_{\mathrm{TOA}, \alpha}$ looks like and is comparable in fractional magnitude to that in surface albedo change with a slight modification by the spatial pattern of the mean RS. The spread in the spatial average of these $10000 \mathrm{RI}_{\mathrm{TOA}, \alpha}$ is combined with the uncertainty in global mean temperature changes-propagated in quadrature since both quantities are scalars-to produce a probability distribution function of SIAF (dark black distribution in left panels of
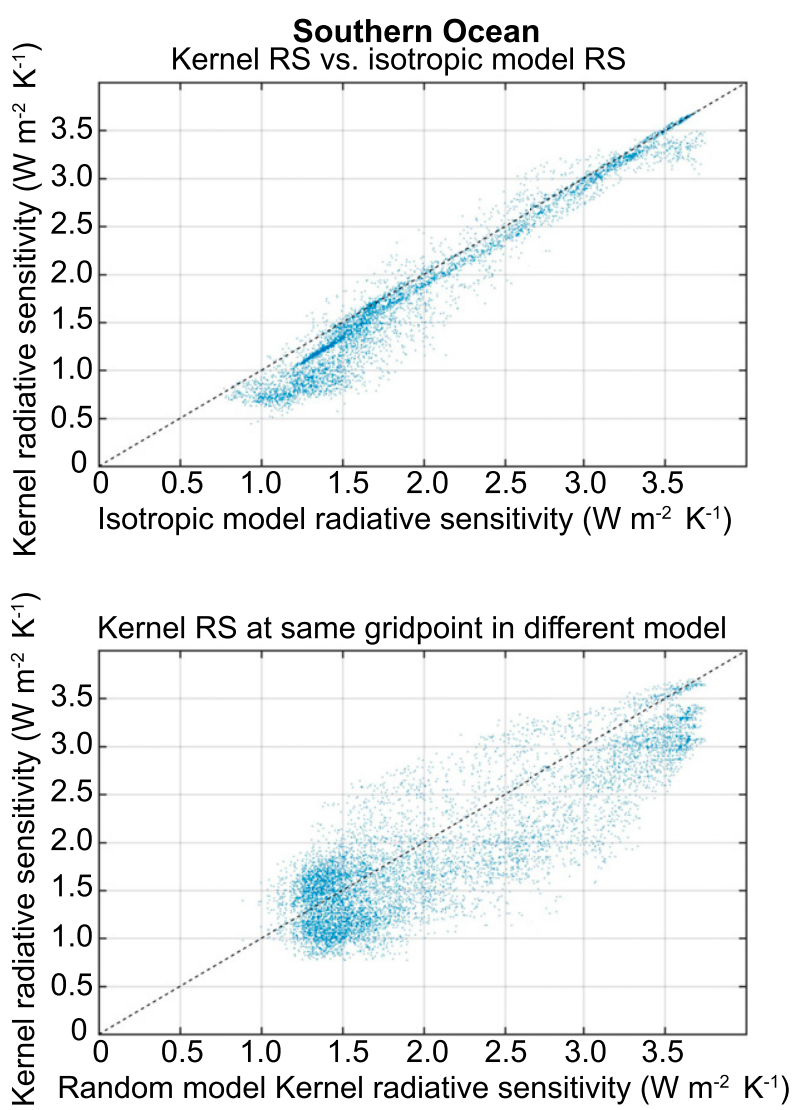

FIG. A3. (top) Scatterplot of NDJFM radiative sensitivity calculated by (ordinate) radiative kernels and (abscissa) the isotropic model from the mean state in the same climate model. All four climate models and Southern Ocean grid points considered collectively. (bottom) Scatterplot of NDJF radiative sensitivity calculated from radiative kernels in one model vs the radiative sensitivity calculated from radiative kernels in a different model (selected at random). The dashed black line shows the 1:1 line.

Fig. 9). These calculations give an Arctic SIAF of $0.14 \pm$ $0.4 \mathrm{~W} \mathrm{~m}^{-2} \mathrm{~K}^{-1}$ where the uncertainty is taken as $2 \sigma$.

The uncertainty in the observational global SIAF can be decomposed into contributions from the RS and IS uncertainty as follows: 1) the contribution of RS is calculated as $2 \sigma$ of the distribution derived from the 100 estimates of RS and multiplied by the OBE IS and 2) the contribution of IS is calculated as $2 \sigma$ of the distribution derived from the 100 estimates of IS and multiplied by the mean RS. The uncertainty in the observational SIAF is almost entirely $\left( \pm 0.04 \mathrm{~W} \mathrm{~m}^{-2} \mathrm{~K}^{-1}\right)$ due to uncertainty in the IS (dark blue narrow distribution in Fig. 9) whereas the uncertainty in the RS contributes very little to the global uncertainty in the SIAF $\left( \pm 0.003 \mathrm{~W} \mathrm{~m}^{-2} \mathrm{~K}^{-1}\right.$; the very narrow dark red distribution in the left of Fig. 9a). 


\section{Albedo Change 1982-2016}

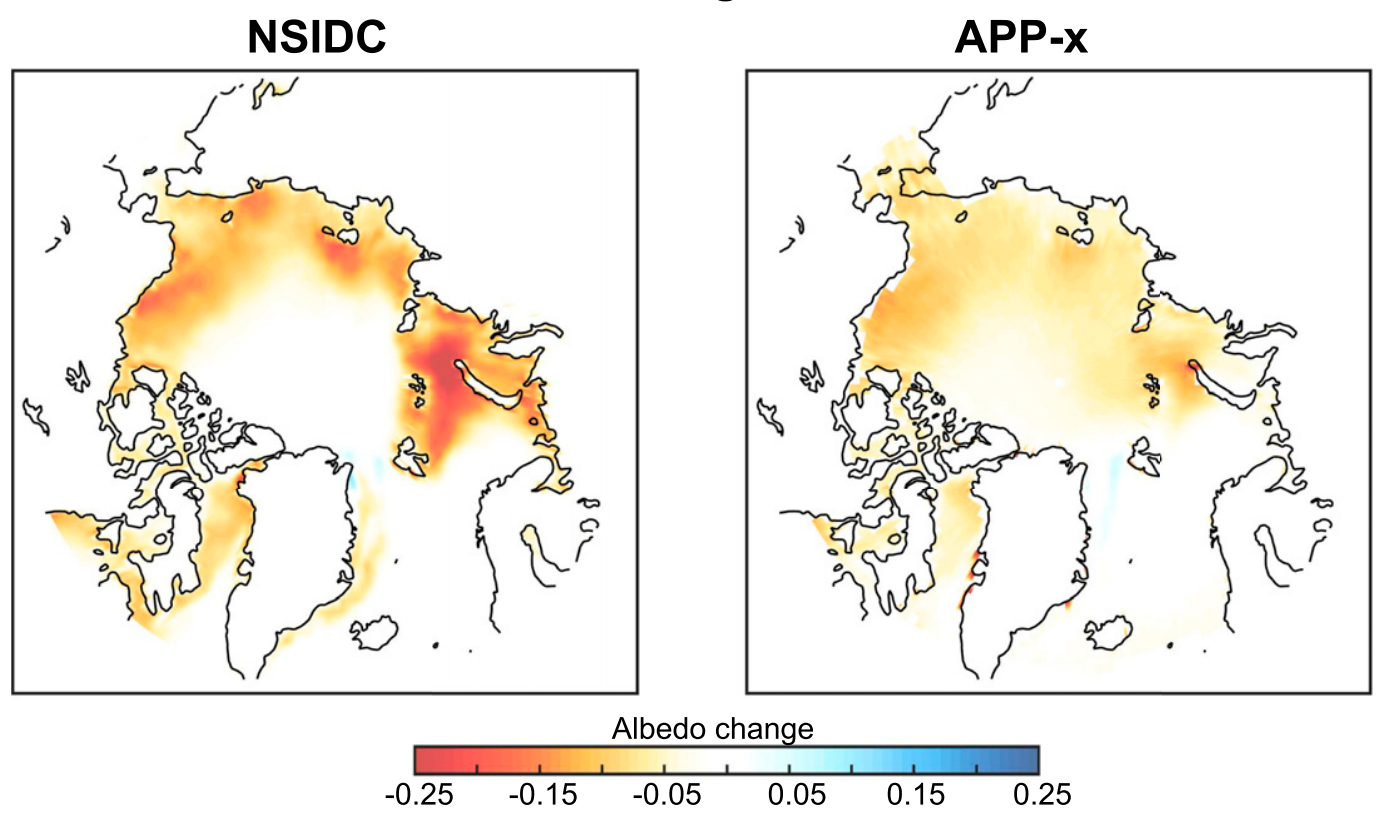

FIG. A4. Comparison of the (MJJA) surface albedo changes (1982-2016) calculated from (left) the NSIDC sea ice concentration data and (right) the APP-x surface albedo data.

\section{REFERENCES}

Armour, K., 2017: Energy budget constraints on climate sensitivity in light of inconstant climate feedbacks. Nat. Climate Change, 7, 331-335, https://doi.org/10.1038/nclimate3278.

Block, K., and T. Mauritsen, 2013: Forcing and feedback in the MPIESM-LR coupled model under abruptly quadrupled $\mathrm{CO}_{2}$. J. $A d v$. Model. Earth Syst., 5, 676-691, https://doi.org/10.1002/jame.20041.

Bony, S., and Coauthors, 2006: How well do we understand climate change feedback processes? J. Climate, 19, 3445-3482, https:// doi.org/10.1175/JCLI3819.1.

Budyko, M., 1969: The effect of solar radiation variations on the climate of the Earth. Tellus, 21, 611-619, https://doi.org/ 10.3402/tellusa.v21i5.10109.

Cao, Y., S. Liang, X. Chen, and T. He, 2015: Assessment of sea ice albedo radiative forcing and feedback over the Northern Hemisphere from 1982 to 2009 using satellite and reanalysis data. J. Climate, 28, 1248-1259, https://doi.org/10.1175/JCLID-14-00389.1.

Cavalieri, D., C. Parkinson, P. Gloersen, and H. Zwally, 1996: Sea ice concentrations from Nimbus-7 SMMR and DMSP SSM/I-SSMIS passive microwave data. NASA National Snow and Ice Data Center Distributed Active Archive Center, accessed 7 January 2019, https://doi.org/10.5067/8GQ8LZQVL0VL.

Chou, M., and K. Lee, 1996: Parameterizations for the absorption of solar radiation by water vapor and ozone. J. Atmos. Sci., 53, 1203-1208, https://doi.org/10.1175/1520-0469(1996)053<1203: PFTAOS $>2.0 . \mathrm{CO} ; 2$.

Cowtan, K., and R. Way, 2014: Coverage bias in the HadCRUT4 temperature series and its impact on recent temperature trends. Quart. J. Roy. Meteor. Soc., 140, 1935-1944, https://doi.org/10.1002/qj.2297.

Curry, J., J. Scramm, and E. Ebert, 1995: Sea ice-albedo climate feedback mechanism. J. Climate, 8, 240-247, https://doi.org/ 10.1175/1520-0442(1995)008<0240:SIACFM $>2.0 . C O ; 2$.
Ding, Q., and Coauthors, 2017: Influence of high-latitude atmospheric circulation changes on summertime Arctic sea ice. Nat. Climate Change, 7, 289-295, https://doi.org/10.1038/ nclimate3241.

- A. Schweiger, M. L. Heureux, E. Steig, D. Battisti, and N. Johnson, 2019: Fingerprints of internal drivers of Arctic sea ice loss in observations and model simulations. Nat. Geosci., 12, 28-33, https://doi.org/10.1038/s41561-018-0256-8.

Donohoe, A., and D. Battisti, 2011: Atmospheric and surface contributions to planetary albedo. J. Climate, 24, 4402-4417, https://doi.org/10.1175/2011JCLI3946.1.

$\longrightarrow$, and - 2013: The seasonal cycle of atmospheric heating and temperature. J. Climate, 26, 4962-4980, https://doi.org/ 10.1175/JCLI-D-12-00713.1.

Ferreira, D., J. Marshall, and B. Rose, 2011: Climate determinism revisited: Multiple equilibria in a complex climate model. J. Climate, 24, 992-1012, https://doi.org/10.1175/ 2010JCLI3580.1.

Flanner, M., K. Shell, M. Barlage, D. Perovich, and M. Tschudi, 2011: Radiative forcing and albedo feedback from the Northern Hemisphere cryosphere between 1979 and 2008. Nat. Geosci., 4, 151-155, https://doi.org/10.1038/NGEO1062.

Flato, G., and Coauthors, 2013: Evaluation of climate models. Climate Change 2013: The Physical Science Basis, T. F. Stocker et al., Eds., Cambridge University Press, 741-866, https:// doi.org/10.1017/CBO9781107415324.018.

Gorodetskaya, I. V., L. Tremblay, B. Liepert, M. A. Cane, and R. Cullather, 2008: The influence of cloud and surface properties on the Arctic Ocean shortwave radiation budget in coupled models. J. Climate, 21, 866-882, https://doi.org/10.1175/ 2007JCLI1614.1.

Hall, A., 2004: The role of surface albedo feedback in climate. J. Climate, 17, 1550-1568, https://doi.org/10.1175/1520-0442(2004) 017<1550:TROSAF $>2.0$. CO;2. 
- and X. Qu, 2006: Using the current seasonal cycle to constrain snow albedo feedback in future climate change. Geophys. Res. Lett., 33, 1550-1568, https://doi.org/10.1029/2005GL025127.

Hansen, J., G. Russell, D. Rind, P. Stone, A. Lacis, S. Lebedeff, R. Ruedy, and L. Travis, 1983: Efficient three-dimensional global models for climate studies: Models I and II. Mon. Wea. Rev., 111, 609-662, https://doi.org/10.1175/1520-0493(1983) 111<0609:ETDGMF>2.0.CO;2.

—_, R. Ruedy, J. Glascoe, and M. Sato, 1999: GISS analysis of surface temperature change. J. Geophys. Res., 104, $30997-$ 31 022, https://doi.org/10.1029/1999JD900835.

Holland, M. M., and C. Bitz, 2003: Polar amplification of climate change in coupled models. Climate Dyn., 21, 221-232, https:// doi.org/10.1007/s00382-003-0332-6.

Hummel, J., and R. Reck, 1979: A global surface albedo model. J. Adv. Model. Earth Syst., 18, 239-253, https://doi.org/ 10.1175/1520-0450(1979)18[239:AGSAM]2.0.CO;2.

Hwang, Y., D. Frierson, and J. Kay, 2011: Coupling between Arctic feedbacks and changes in poleward energy transport. Geophys. Res. Lett., 38, L17704, https://doi.org/10.1029/2011GL048546.

Jones, J., and Coauthors, 2016: Assessing recent trends in highlatitude Southern Hemisphere surface climate. Nat. Climate Change, 6, 917-926, https://doi.org/10.1038/nclimate3103.

Kalnay, E., and Coauthors, 1996: The NCEP/NCAR 40-Year Reanalysis Project. Bull. Amer. Meteor. Soc., 77, 437-471, https:// doi.org/10.1175/1520-0477(1996)077<0437:TNYRP>2.0.CO;2.

Kato, S., and Coauthors, 2018: Surface irradiances of edition 4.0 Clouds and the Earth's Radiant Energy System (CERES) Energy Balanced and Filled (EBAF) data product. J. Climate, 31, 4501-4527, https://doi.org/10.1175/JCLI-D-17-0523.1.

Kay, J., M. Holland, and A. Jahn, 2011: Inter-annual to multi-decadal Arctic sea ice extent trends in a warming world. Geophys. Res. Lett., 38, L15708, https://doi.org/10.1029/2011GL048008.

— — C. Bitz, E. Blanchard-Wrigglesworth, A. Gettelman, A. Conley, and D. Bailey, 2012: The influence of local feedbacks and northward heat transport on the equilibrium Arctic climate response to increased greenhouse gas forcing. J. Climate, 25, 5433-5450, https://doi.org/10.1175/JCLI-D-11-00622.1.

Lindsay, R., M. Wensnaham, A. Schweiger, and J. Zhang, 2014: Evaluation of seven different atmospheric reanalysis products in the Arctic. J. Climate, 27, 2588-2606, https://doi.org/10.1175/ JCLI-D-13-00014.1.

Loeb, N. G., and Coauthors, 2018: Clouds and the Earth's Radiant Energy System (CERES) Energy Balanced and Filled (EBAF) top-of-atmosphere (TOA) edition-4.0 data product. J. Climate, 31, 895-918, https://doi.org/10.1175/JCLI-D-17-0208.1.

Mahlstein, I., and R. Knutti, 2012: September Arctic sea ice predicted to disappear near $2^{\circ} \mathrm{C}$ global warming above present. J. Geophys. Res., 117, D06104, https://doi.org/10.1029/ 2011JD016709.

Meehl, G. A., C. Covey, T. Delworth, M. Latif, B. McAvaney, J. F. B. Mitchell, R. J. Stouffer, and K. E. Taylor, 2007: The WCRP CMIP3 multi-model dataset: A new era in climate change research. Bull. Amer. Meteor. Soc., 88, 1383-1394, https://doi.org/10.1175/BAMS-88-9-1383.

Morice, C. P., J. Kennedy, N. Rayner, and P. Jones, 2012: Quantifying uncertainties in global and regional temperature change using an ensemble of observational estimates: The HadCRUT4 dataset. J. Geophys. Res., 117, D08101, https:// doi.org/10.1029/2011JD017187.

North, G. R., 1984: The small ice cap instability in diffusive climate models. J. Atmos. Sci., 41, 3390-3395, https://doi.org/10.1175/ 1520-0469(1984)041<3390:TSICII>2.0.CO;2.
Pendergrass, A. G., A. Conley, and F. M. Vitt, 2018: Surface and top-of-atmosphere radiative feedback kernels for CESMCAM5. Earth Syst. Sci. Data, 10, 317-324, https://doi.org/ 10.5194/essd-10-317-2018.

Perovich, D., T. Grenfell, B. Light, and P. Hobbs, 2002: Seasonal evolution of the albedo of multiyear Arctic sea ice.J. Geophys. Res., 107, 8044, https://doi.org/10.1029/2000JC000438.

Pistone, K., I. Eisenman, and V. Ramanathan, 2014: Observational determination of albedo decrease caused by vanishing Arctic sea ice. Proc. Natl. Acad. Sci., 111, 3322-3326, https://doi.org/ 10.1073/pnas.1318201111.

- — - and — 2019: Radiative heating of an ice-free Arctic Ocean. Geophys. Res. Lett., 46, 7474-7480, https://doi.org/ 10.1029/2019GL082914.

Polvani, L., and K. Smith, 2013: Can natural variability explain the observed Antarctic sea ice trends? New modeling evidence from CMIP5. Geophys. Res. Lett., 40, 3195-3199, https:// doi.org/10.1002/grl.50578.

Previdi, M., 2010: Radiative feedbacks on global precipitation. Environ. Res. Lett., 5, 025211, https://doi.org/10.1088/17489326/5/2/025211.

Qu, X., and A. Hall, 2005: Surface contribution to planetary albedo variability in the cryosphere regions. J. Climate, 18, 5239-5252, https://doi.org/10.1175/JCLI3555.1.

Roe, G., 2009: Feedbacks, timescales, and seeing red. Аnnu. Rev. Earth Planet. Sci., 37, 930115, https://doi.org/10.1146/ ANNUREV.EARTH.061008.134734.

Rosenblum, E., and I. Eisenman, 2016: Faster Arctic sea ice retreat in CIMP5 than in CMIP3 due to volcanoes. J. Climate, 29, 9179-9188, https://doi.org/10.1175/JCLI-D-16-0391.1.

Schneider, A., M. Flanner, and J. Perket, 2018: Multidecadal variability in surface albedo feedback across CMIP5 models. Geophys. Res. Lett., 45, 1972-1980, https://doi.org/10.1002/ 2017 GL076293.

Shell, K., J. Kiehl, and C. Shields, 2008: Using the radiative kernel technique to calculate climate feedbacks in NCAR's Community Atmospheric Model. J. Climate, 21, 2269-2282, https://doi.org/ 10.1175/2007JCLI2044.1.

Shu, Q., Z. Song, and F. Qiao, 2015: Assessment of sea ice simulations in the CMIP5 models. Cryosphere, 9, 399-409, https:// doi.org/10.5194/tc-9-399-2015.

Sledd, A., and T. L'Ecuyer, 2019: How much do clouds mask the impact of Arctic sea ice and snow cover variations? Different perspectives from observations and reanalyses. Atmosphere, 10, 12, https://doi.org/10.3390/atmos10010012.

Smith, C., and Coauthors, 2018: Understanding rapid adjustments to diverse forcing agents. Geophys. Res. Lett., 45, 12023 12 031, https://doi.org/10.1029/2018GL079826.

Soden, B., and I. Held, 2006: An assessment of climate feedbacks in coupled ocean-atmosphere models. J. Climate, 19, 3354-3360, https://doi.org/10.1175/JCLI3799.1.

Stocker, T., and Coauthors, 2013: Technical summary. Climate Change 2013: The Physical Science Basis, T. F. Stocker et al., Eds., Cambridge University Press, 33-115, https://doi.org/10.1017/ CBO9781107415324.005.

Stroeve, J., and D. Notz, 2015: Insights on past and future seaice evolution from combining observations and models. Global Planet. Change, 135, 119-132, https://doi.org/10.1016/ j.gloplacha.2015.10.011.

Taylor, K., M. Crucifix, P. Braconnot, C. Hewitt, C. Doutriaux, A. Broccoli, J. Mitchell, and M. Webb, 2007: Estimating shortwave radiative forcing and response in climate models. J. Climate, 20, 2530-2543, https://doi.org/10.1175/JCLI4143.1. 
- R. Stouffer, and G. Meehl, 2012: An overview of cmip5 and the experiment design. Bull. Amer. Meteor. Soc., 93, 485-498, https://doi.org/10.1175/BAMS-D-11-00094.1.

Trenberth, K. E., and J. T. Fasullo, 2010: Simulation of presentday and twenty-first-century energy budgets of the southern oceans. J. Climate, 23, 440-454, https://doi.org/10.1175/ 2009JCLI3152.1.

Vavrus, S., D. Waliser, A. Schweiger, and J. Francis, 2009: Simulations of 20th and 21st century Arctic cloud amount in the global climate models assessed in the IPCC AR4. Climate Dyn., 33, 1099-1115, https://doi.org/10.1007/s00382-008-0475-6.

Wang, X., and J. Key, 2005: Arctic surface, cloud, and radiation properties based on the AVHRR Polar Pathfinder dataset. Part I: Spatial and temporal characteristics. J. Climate, 18, 2558-2574, https://doi.org/10.1175/JCLI3438.1.

Winton, M., 2006: Surface albedo feedback estimates from the AR4 climate models. J. Climate, 19, 359-365, https://doi.org/ 10.1175/JCLI3624.1. 